\title{
Tyrosine kinase inhibitor NVP-BGJ398 functionally improves FGFR3-related dwarfism in mouse model
}

\author{
Davide Komla-Ebri, ${ }^{1}$ Emilie Dambroise, ${ }^{1}$ Ina Kramer, ${ }^{2}$ Catherine Benoist-Lasselin, ${ }^{1}$ Nabil Kaci, ${ }^{1}$ Cindy Le Gall, ${ }^{1}$ Ludovic Martin, \\ Patricia Busca, ${ }^{3}$ Florent Barbault, ${ }^{4}$ Diana Graus-Porta, ${ }^{2}$ Arnold Munnich, ${ }^{1,5}$ Michaela Kneissel, ${ }^{2}$ Federico Di Rocco, ${ }^{1}$ \\ Martin Biosse-Duplan, ${ }^{1,6}$ and Laurence Legeai-Mallet ${ }^{1,5}$ \\ ${ }^{1}$ INSERM U1163, Université Paris Descartes, Sorbonne Paris Cité, Institut Imagine, Paris, France. ${ }^{2}$ Novartis Institutes for BioMedical Research, Basel, Switzerland. ${ }^{3}$ University Paris Descartes, UMR 8601 CNRS, \\ Paris, France. ${ }^{4}$ University Paris Diderot, Sorbonne Paris Cité, ITODYS, UMR CNRS 7086, Paris, France. ${ }^{5}$ Service de Génétique, Hôpital Necker-Enfants Malades, Assistance Publique - Hôpitaux de Paris \\ (AP-HP), Paris, France. ${ }^{6}$ France Service d'Odontologie, Hôpital Bretonneau, Hôpitaux Universitaires Paris Nord Val de Seine (HUPNVS), AP-HP, Paris, France.
}

\begin{abstract}
Achondroplasia (ACH) is the most frequent form of dwarfism and is caused by gain-of-function mutations in the fibroblast growth factor receptor 3-encoding (FGFR3-encoding) gene. Although potential therapeutic strategies for ACH, which aim to reduce excessive FGFR3 activation, have emerged over many years, the use of tyrosine kinase inhibitor (TKI) to counteract FGFR3 hyperactivity has yet to be evaluated. Here, we have reported that the pan-FGFR TKI, NVP-BGJ398, reduces FGFR3 phosphorylation and corrects the abnormal femoral growth plate and calvaria in organ cultures from embryos of the Fgfr $^{\mathrm{r} 367 \mathrm{C} /+}$ mouse model of ACH. Moreover, we demonstrated that a low dose of NVP-BGJ398, injected subcutaneously, was able to penetrate into the growth plate of $\mathrm{Fgfr}^{\mathrm{r} 367 \mathrm{C} /+}$ mice and modify its organization. Improvements to the axial and appendicular skeletons were noticeable after 10 days of treatment and were more extensive after 15 days of treatment that started from postnatal day 1. Low-dose NVP-BGJ398 treatment reduced intervertebral disc defects of lumbar vertebrae, loss of synchondroses, and foramen-magnum shape anomalies. NVP-BGJ398 inhibited FGFR3 downstream signaling pathways, including MAPK, SOX9, STAT1, and PLC $\gamma$, in the growth plates of $\mathrm{Fgfr}^{\mathrm{r} 367 \mathrm{Cl}+}$ mice and in cultured chondrocyte models of ACH. Together, our data demonstrate that NVP-BGJ398 corrects pathological hallmarks of ACH and support TKIs as a potential therapeutic approach for ACH.
\end{abstract}

\section{Introduction}

Achondroplasia $(\mathrm{ACH})$ is the most common form of dwarfism, which occurs with an estimated prevalence of between $1 / 16,000$ and $1 / 25,000$ live births $(1,2)$. ACH patients are characterized by disproportionate short stature, with a long trunk deformed by excessive lordosis. The head is large with frontal bossing and the midface is hypoplastic (2). ACH is an autosomal-dominant disorder, and patients with $\mathrm{ACH}$ have been found to have a gainof-function mutation (p.Gly380Arg) localized in the transmembrane domain of the fibroblast growth factor receptor 3 (FGFR3), a member of the receptor tyrosine kinase family $(3,4)$. The FGFR3 mutation disturbs the balance of proliferation and differentiation in the growth plate. Several papers reported both decreased and increased proliferation related to stage-specific development $(5-8)$. Chondrocyte differentiation is also impaired $(9,10)$ and seems to be controlled by SRY-box 9 (Sox9) expression in the growth plate (11). The ACH mutation activates the tyrosine kinase activity of the receptor and facilitates the transautophosphorylation of key tyrosine residues in the intracellular domain and activates mainly the downstream canonical MAP pathway. Other signaling pathways have been implicated in addition in $\mathrm{ACH}$, e.g., STAT, Wnt/ $\beta$-catenin, PI3K/AKT, and PLC $\gamma$ pathways $(9,12,13)$.

Conflict of interest: I. Kramer, D. Graus-Porta, and M. Kneissel work for Novartis. Submitted: July 24, 2015; Accepted: February 25, 2016.

Reference information: J Clin Invest. 2016;126(5):1871-1884. doi:10.1172/JCI83926.
Potential therapeutic strategies have emerged for ACH over the last 5 years; these have aimed at reducing excessive activation of FGFR3 and its signaling pathways to stimulate linear bone growth. Our group conducted preclinical studies on a C-natriuretic peptide (CNP) analog (14), BMN111, and we showed that this treatment led to a substantial improvement of skeletal parameters in the Fgfr $3^{\mathrm{Y} 367 \mathrm{C} / \mathrm{+}}$ mouse, which is a preclinical model of ACH (15). BMN111 (vosoritide) is currently in a (phase 2) clinical trial in pediatric patients with ACH (ClinicalTrials.gov NCT02055157). Other preclinical studies using different strategies and various compounds, such as parathyroid hormone (PTH) (16), soluble FGFR3 (17), statin (18), and meclozine (19), reported changes in the dwarf Fgfr $3^{\text {ach }}$ mouse phenotype (7). For most of these strategies, the mechanism of action in the growth plate needs to be elucidated. However, the most direct therapeutic strategy would be to counteract the hyperactivity of FGFR3 using a tyrosine kinase inhibitor (TKI). NVP-BGJ398 was identified as a panspecific FGFR inhibitor that was equally active against FGFR1, FGFR2, and FGFR3 and less active against FGFR4 (20). Recently, cell-free kinase assays showed that NVP-BGJ398 was more selective for FGFR3 than the other FGFRs (21). This TKI is effective in reducing FGFR3 activation and has been used in preclinical murine models for the treatment of several FGFR-related pathological conditions, such as hypophosphatemic rickets (22), malignant rhabdoid tumors (23), and hepatocellular carcinoma (24). We therefore decided to investigate whether NVP-BGJ398 could penetrate into the car- 
A



C

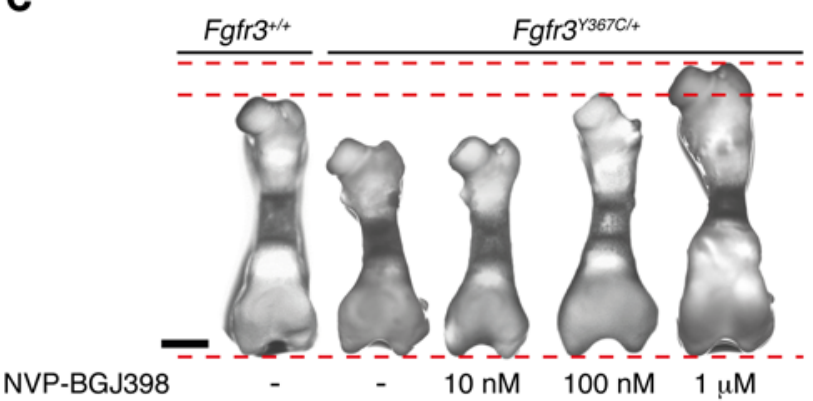

B
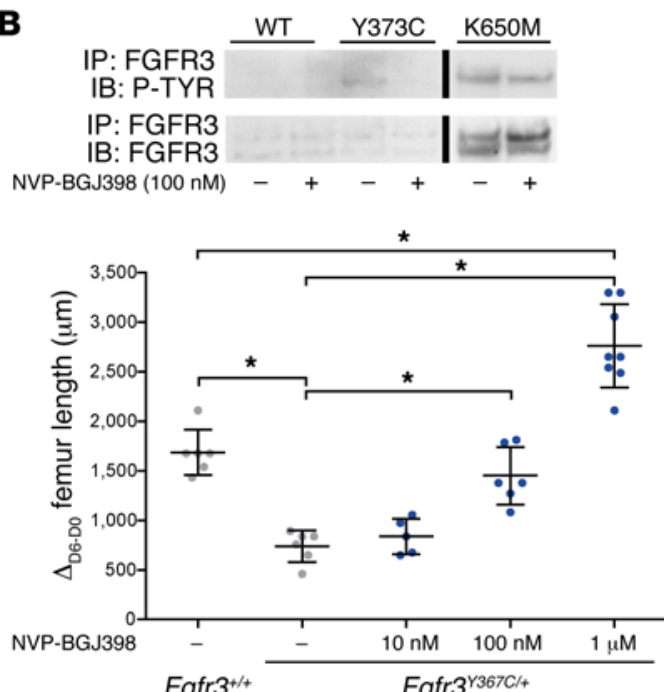

$\mathrm{Fgfr}^{++}$
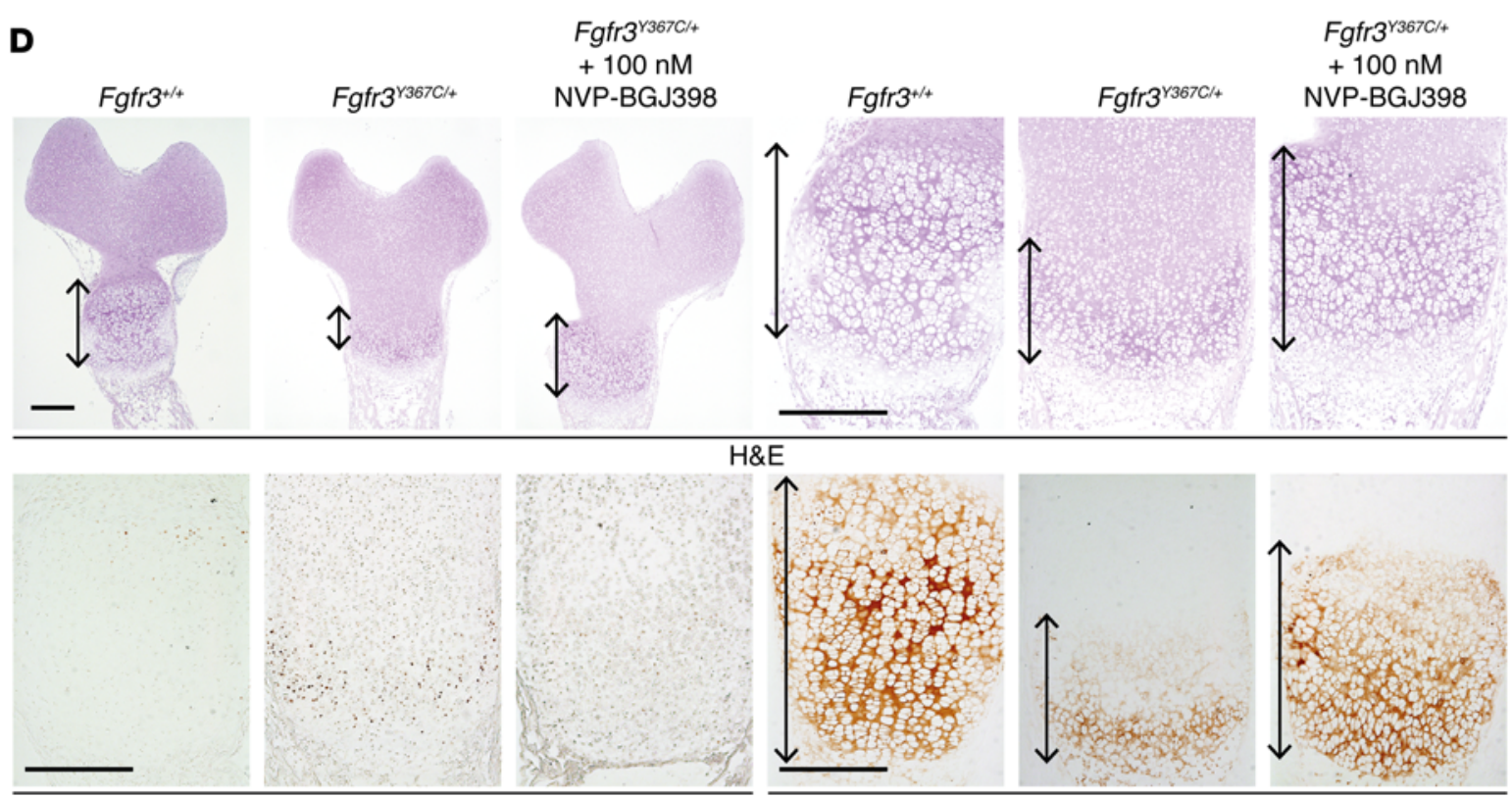

$\mathrm{H} \& \mathrm{E}$

E

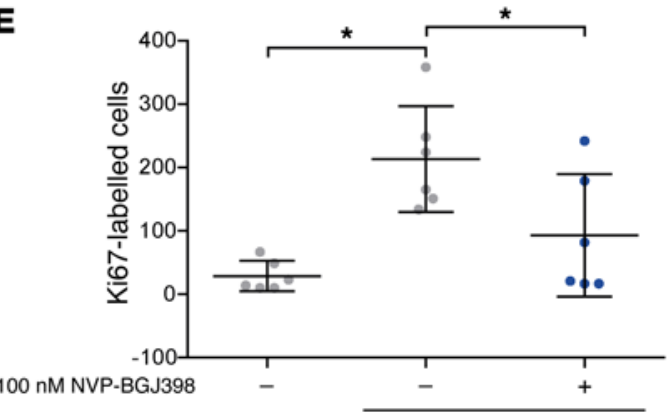

$\mathrm{Fgfr}^{+/+}$ Fgfr3 $^{\text {r } 367 \mathrm{C} / 4} \quad$ NVP-BGJ398
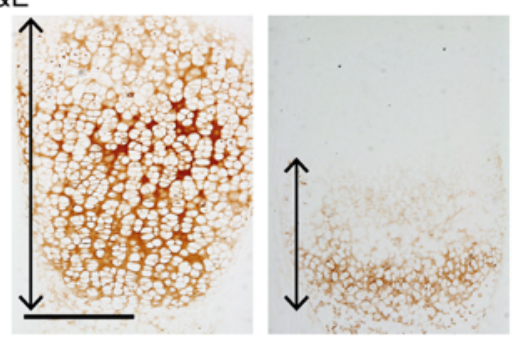

Col X
$\mathbf{F}$

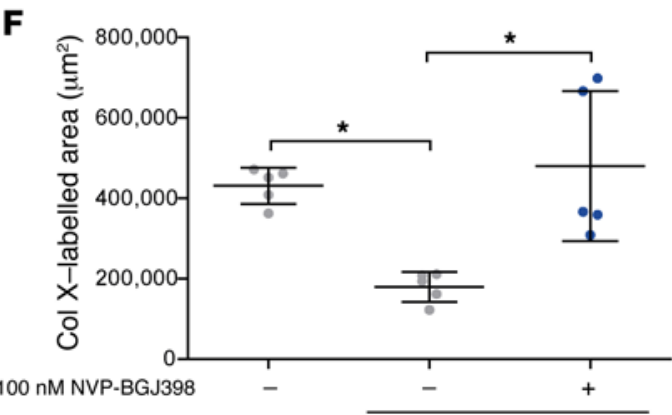

$\mathrm{Fgfr}^{+/ 4}$

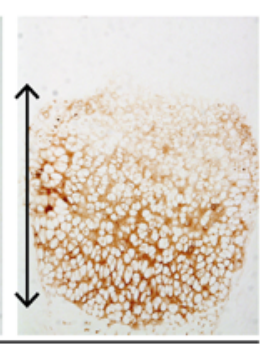

$\mathrm{Fgfr}^{\mathrm{rab7C/4}}$

Figure 1. NVP-BGJ398 inhibits the activation of FGFR3 and rescues ex vivo bone growth of $\mathrm{Fgfr}^{\mathrm{r} 36 \mathrm{6} / \mathrm{/}+}$ mouse embryo femurs. (A) Phosphorylated FGFR3 expression in transfected human chondrocytes with FGFR3 (WT), FGFR3 ${ }^{\mathrm{G} 380 \mathrm{R}}$ (ACH), FGFR3 ${ }^{\mathrm{V} 373 \mathrm{C}}$ (TDI), and FGFR3 ${ }^{\mathrm{K} 650 \mathrm{E}}$ (TDII) constructs. (B) Phosphorylated FGFR3 expression in transfected HEK293-Vnr cells with FGFR3 (WT), FGFR3 ${ }^{\mathrm{Y} 373 \mathrm{C}}$ (TDI), and FGFR3 ${ }^{\mathrm{K} 650 \mathrm{M}}$ (SADDAN) constructs. Lanes were run on the same gel, but were noncontiguous. (C) Gain of length of E16.5 femurs in culture for 6 days $\left(\Delta_{06-00}\right)$ with or without treatment $\left(F g f r 3^{+/+}\right.$,

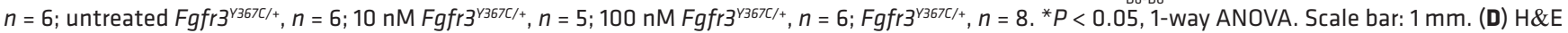
staining and immunohistochemistry for Col $\mathrm{X}$ and Ki67 on embryonic distal femur following 6 days of culture with or without treatment. Arrows indicate hypertrophic area. Scale bars: $200 \mu \mathrm{m}$. (E) Number of Ki67-labeled cells in treated and untreated $\mathrm{Fgfr}^{\mathrm{Y} 367 \mathrm{C} /{ }_{+}}$compared with $\mathrm{Fgfr}^{+/+}$embryonic femur ( $n=6$ per group). ${ }^{*} P<0.05$, 1-way ANOVA. (F) Col X-labeled growth plate area in $\mathrm{Fgfr}^{+/+}$and $\mathrm{Fgfr}^{\mathrm{\gamma} 36 \mathrm{Cl} /+}$ treated and untreated embryonic femur $(n=5$ per group). ${ }^{*} P<0.05,1$-way ANOVA. Western blots are representative of 3 independent experiments. Data are expressed as mean \pm SD. 
Table 1. Improvement of femur lengths after NVP-BGJ398 treatment
$\mathrm{Fgfr3}^{+/+}$
$\mathrm{Fgfr}^{\mathrm{Y} 367 \mathrm{Cl}+}$
Fgfr $\left.^{\mathrm{Y} 367 / /+}+\mathrm{NVP}-\mathrm{BC}\right] 398,10 \mathrm{nM}$
Fgfr3 $\left.{ }^{\mathrm{Y} 367 /++}+\mathrm{NVP}-\mathrm{BC}\right] 398,100 \mathrm{nM}$
$5,311 \pm 127 \mu \mathrm{m}$
$\mathrm{Fgfr}^{\mathrm{Y} 367 / /+}+\mathrm{NVP}-\mathrm{BC} \mid 398,1 \mu \mathrm{M}$
$6,702 \pm 151 \mu \mathrm{m}$
$5,604 \pm 144 \mu \mathrm{m}$
$4,667 \pm 104 \mu \mathrm{m}$
$4,659 \pm 61 \mu \mathrm{m}$

Size of femurs after 6 days of culture with NVP-BGJ398. Data are expressed as mean \pm SD.

tilage and bone and improve the skeletal phenotype in ACH via its inhibitory action on FGFR3 and downstream signaling pathways. In our study, NVP-BGJ398 inhibited the hyperactivity of FGFR3 and the canonical MAPK in ACH human cartilage cells. NVP-BGJ398 rescued the anomalies of fetal calvaria and femur in organ cultures of tissue taken from the $\mathrm{Fg} f \mathrm{r} 3^{\mathrm{Y} 367 \mathrm{C} /{ }^{+}}$mouse model of ACH. Moreover, NVP-BGJ398 treatment of Fgfr $3^{\mathrm{Y367C/+}}$ mice was able to correct the dwarf phenotype. The reduction in the activity of FGFR3 improved all pathological hallmarks of ACH in long bones, skull base, calvaria, intervertebral disc (IVD), and vertebrae. The timing and type of the treatment were 2 important criteria for the improvement of bone growth in $\mathrm{Fg} f 3^{\mathrm{Y3} 67 \mathrm{C} /+}$ mice. At cellular and tissue levels, chondrocyte proliferation was restored, as demonstrated by STAT pathway downregulation, and chondrocyte differentiation was improved, as demonstrated by SOX 9 and MAPK downregulation. Our data suggest that TKIs may represent a pharmacological approach for the treatment of FGFR3 hyperactivation-related disorders.

\section{Results}

NVP-BGJ398 inhibits FGFR3 phosphorylation. We evaluated the ability of NVP-BGJ398 to inhibit FGFR3 phosphorylation in transiently transfected human control chondrocyte lines (Figure 1A) and HEK293-Vnr cells (Figure 1B). Cells were transfected with constructs expressing FGFR3 $3^{\mathrm{WT}}$ and FGFR3 gain-of-function mutations localized in different domains of FGFR3 responsible for chondrodysplasias (FGFR3 ${ }^{\mathrm{G} 380 \mathrm{R}}$ [transmembrane domain; $\mathrm{ACH}$ ], FGFR3 ${ }^{\mathrm{Y} 373 \mathrm{C}}$ [extracellular domain; thanatophoric dysplasia type 1 [TDI], FGFR3 ${ }^{K 650 E}$ intracellular domain; thanatophoric dysplasia type 2 [TDII]) $(25,26)$. Twenty-four hours after transfection, phosphorylated FGFR3 was detected for each mutant (Figure 1, A and B). For all transfected cells expressing FGFR3 with activating mutations, NVP-BGJ398 reduced FGFR3 phosphorylation (Figure 1, A and B). No phosphorylated FGFR $3^{\mathrm{WT}}$ was detected in HEK293Vnr cells (Figure 1B).

NVP-BGJ398 restores bone growth in Fgfr $3^{\mathrm{Y367C/+}}$ embryonic femurs. In ACH, FGFR3-activating mutations disturb endochondral and membranous ossifications $(27,28)$. Our in vitro findings therefore prompted us to test the impact of NVP-BGJ398 on long bone and skull growth. To investigate the effect on endochondral ossification, we used ex vivo cultures of embryonic femurs isolated from $\mathrm{Fgfr} 3^{\mathrm{Y367C/+}}$ mice (E16.5) with various concentrations of NVP-BGJ398. At day 6, untreated Fgfr $3^{\mathrm{Y367C/+}}$ femurs exhibited a reduction of length $(-16.7 \%)$ compared with WT femurs (Figure $1 \mathrm{C}$ and Table 1). Six days of ex vivo culture with $10 \mathrm{nM}$ NVPBGJ398 did not affect bone growth of WT femurs, whereas 100 nM NVP-BGJ398 rescued completely the bone growth defect of Fgfr $3^{\mathrm{Y3} 37 \mathrm{C} / \mathrm{+}}$ femurs (Figure $1 \mathrm{C}$ and Table 1). At $1 \mu \mathrm{M}, \mathrm{NVP}-\mathrm{BGJ} 398$ induced bone overgrowth of $\mathrm{Fg} f r 3^{\mathrm{Y3} 67 \mathrm{C} /+}$ femurs $(+19.6 \%$ compared with WT femurs, $+43.6 \%$ compared with untreated $\mathrm{Fg} f \mathrm{r} 3^{\mathrm{Y} 367 \mathrm{C} /+}$ femurs). These data show that the induced femoral elongation by NVP-BGJ398 was dose dependent, confirming the role of FGFR3 as a negative regulator of bone growth (5).

In Fgfr $3^{\mathrm{Y} 367 \mathrm{C} /+}$ mice, the coordinated proliferation and differentiation of chondrocytes that ensure the continuous elongation of the growth plate are defective (29). We observed that in Fgfr $3^{\mathrm{Y3} 67 \mathrm{C} /+}$ explants cultured for 6 days, chondrocyte proliferation (i.e., Ki67 expression) was increased (7 times more than WT) as previously reported (ref. 26 and Figure 1, D and E). NVP-BGJ398 significantly reduced chondrocyte proliferation at $100 \mathrm{nM}(-56.4 \%$ compared with untreated). Differentiated chondrocytes in the growth plate were assessed using an antibody against collagen X (Col X), and we observed that the growth-plate hypertrophic zone was reduced in Fgfr $3^{\mathrm{Y} 367 \mathrm{C} /+}$ explants (-58.4\% compared with WT) as previously reported (refs. 15, 30, and Figure 1, D and F). The area of the hypertrophic zone was increased ( $+167.6 \%)$ with NVP-BGJ398 treatment compared with vehicle alone, indicating that the defective differentiation of the chondrocytes was ameliorated (Figure 1, D and F).

To analyze the membranous ossification defect in the Fgfr $3^{\mathrm{Y3} 37 \mathrm{C} /+}$ skull vault, we used ex vivo cultures of embryonic mouse calvaria. Previously, we reported a calvarial defect in $\mathrm{ACH}$ and Fgfr $3^{\mathrm{Y3} 67 \mathrm{C} / \mathrm{+}}$ mice, indicating a role of FGFR3 in skull bone growth (28). This defect gradually disappears during skull growth, as it does in mouse calvaria cultures. We observed that the calvarial defect, corresponding to a bone ossification delay, resolved faster and more completely in NVP-BGJ398-treated cultures (100 $\mathrm{nM}$ ) compared with untreated $\mathrm{Fg} f \mathrm{r}^{\mathrm{Y} 367 \mathrm{C} /{ }^{+}}$calvaria from culture day $4(+20.1 \%)$ to culture day 14 (+46.1\%) (Figure 2, A and B). These data confirm that the calvaria-formation defect is directly related to the overactivation of FGFR3.

Together, these results indicate that in ex vivo bone models of ACH, NVP-BGJ398 can rescue chondrocyte proliferation and differentiation defects and can reduce the bone-growth anomalies of the growth plate and the skull vault, thus modifying both chondrogenesis and osteogenesis during embryonic bone development.

NVP-BGJ398 improves growth of the appendicular skeleton in Fgfr $3^{\mathrm{Y} 367 \mathrm{C} / \mathrm{+}}$ mice. On the basis of those encouraging in vitro and ex vivo data, we treated $F g f r 3^{\mathrm{Y} 367 \mathrm{C} /+}$ newborn mice (P1) daily with subcutaneous injections of NVP-BGJ398 ( $2 \mathrm{mg}$ per $\mathrm{kg}$ body weight per day) for 15 days (protocol 1). The Fgfr $3^{\mathrm{Y367C/+}}$ mouse phenotype mimics human ACH in several respects; short stature, macrocephaly, prognatism, fused synchondroses, and foramen magnum (FM) stenosis $(28,29)$. Our objective was to evaluate whether and how NVP-BGJ398 inhibition of the overactivity of FGFR3 would affect bone growth in vivo. The treatment was well tolerated by Fgfr $3^{\mathrm{Y3} 67 \mathrm{C} /+}$ and $\mathrm{Fgfr}^{+/+}$mice without noticeable modification of behavior.

$\mathrm{X}$-ray analyses of the forelimbs (Figure 3A) and hind limbs (Figure 3B) showed in NVP-BGJ398-treated Fgfr $3^{\mathrm{Y} 367 \mathrm{C} /+}$ mice a 
A


B



Figure 2. NVP-BGJ398 reduces the ossification gap of $\mathrm{Fgfr}^{\mathrm{r} 367 \mathrm{Cl} / \mathrm{+}}$ mouse embryo calvariae ex vivo. (A) Fetal calvaria gaps of $\mathrm{Fgfr}^{\mathrm{r} 367 \mathrm{Cl}+}$ mice with or without treatment are indicated by white lines. Magnified images show the effects on suture. (B) The modifications of calvaria gap size of the $\mathrm{Fgfr}^{\mathrm{Y} 367 \mathrm{Cl} /+}$ treated mice $(n=11)$ compared with the untreated Fgfr $^{\mathrm{r} 367 \mathrm{C} /+}$ mice $(n=5)$ are indicated in the graph. ${ }^{*} P<0.05$, Mann-Whitney $U$ test. Scale bars: $1 \mathrm{~mm}$. Data are expressed as mean $\pm \mathrm{SD}$. distinct increase in size of these limbs compared with those of control Fgfr $3^{\mathrm{Y} 367 \mathrm{C} /+}$ littermates. At necropsy, long bones of treated Fgfr $3^{\mathrm{Y} 367 \mathrm{C} /+}$ mice (NVP-BGJ398 and vehicle) and their Fgfr $3^{+/+}$control littermates were measured. In $\mathrm{Fg} f \mathrm{r} 3^{\mathrm{Y} 367 \mathrm{C} /+}$ mice, the lengths of proximal and distal long bones were significantly higher with NVP-BGJ398 treatment than control treatment (femur $+20.9 \%$, humerus $+11.9 \%$, tibia $+32.6 \%$, ulna $22.3 \%$, and radius $+24.1 \%$ ) (Figure 3C and Supplemental Figure 1A; supplemental material available online with this article; doi:10.1172/JCI83926DS1). $\mu \mathrm{CT}$ imaging confirmed these data and also showed that NVPBGJ398 treatment expanded the total cross-sectional tissue area of $\mathrm{Fg} f \mathrm{r}^{\mathrm{Y} 367 \mathrm{C} /+}$ mouse distal femur metaphysis (+30\% vs vehicle) (Figure 3, D-F). The long-bone growth of $\mathrm{Fgfr}^{+/+}$mice treated with NVP-BGJ398 was not affected (data not shown), and no premature death was observed, confirming the mild or null effect of the inhibitor on $\mathrm{Fgfr} 3^{+/+}$mice.

Histological analyses of the epiphyseal growth plate of long bones showed that NVP-BGJ398 improved growth-plate cartilage homeostasis in both distal and proximal femurs (Figure 4A) and tibias (Supplemental Figure 1B).

Chondrocyte proliferation was lower in $\mathrm{Fg} f \mathrm{r}^{\mathrm{Y3} 67 \mathrm{C} /+}$ untreated mice $(-59.9 \%)$ compared with $\mathrm{Fgfr}^{+/+}$mice, as measured with BrdU incorporation into the growth plate. By contrast, chondrocyte proliferation was significantly higher with NVP-BGJ398 treatment than control treatment in Fgfr $3^{\mathrm{Y} 367 \mathrm{C} /{ }^{+}}$mice $(+162.1 \%)$ (Figure $\left.4 \mathrm{~B}\right)$.

Likewise, the impaired differentiation of hypertrophic chondrocytes in femurs and tibias of $\mathrm{Fg} f \mathrm{~F}^{\mathrm{Y} 367 \mathrm{C} /{ }^{+}}$mice was rescued by NVP-BGJ398 treatment, as demonstrated by Col X immunos- taining (Figure 4C and Supplemental Figure 1B). In these treated mice, the expression of $\mathrm{Col} \mathrm{X}$ was observed in the calcified cartilage, showing an active process of bone growth at the subtrabecular bone level (Figure 4C and Supplemental Figure 1B). Previously, we reported that angiogenesis was disturbed in Fgfr $3^{\mathrm{Y367C/+}}$ mice (29). We hypothesized that the action of NVP-BGJ398 on cartilage could affect angiogenesis in the growth plate and thus activate mineralization reflected by the altered size of the secondary ossification center (Figure 4A, and Supplemental Figure 1B). In support of this hypothesis, CD34, a marker of immature endothelial cells, was higher in the chondroosseous junctions of Fgfr $3^{\mathrm{Y3} 67 \mathrm{C} /+}$ mice with the NVP-BGJ398 treatment in comparison with the control treatment (Supplemental Figure 1C). These data suggest that NVP-BGJ398 treatment increased formation of endothelial sprouts and initiation of angiogenesis in $\mathrm{Fg} f \mathrm{rr}^{\mathrm{Y367C} /+}$ mice.

NVP-BGJ398 improves growth of the axial skeleton in Fgfr $3^{\mathrm{Y} 367 \mathrm{C} /+}$ mice. Most ACH patients exhibit kyphosis, lordosis, platyspondyly, spinal stenosis, and short pedicles, indicating that the axial skeleton is also affected (1). For this reason, we investigated the spine of Fgfr $3^{\mathrm{Y3} 67 \mathrm{C} /+}$ mice. The rate of tail-length growth in $\mathrm{Fgfr} 3^{\mathrm{Y3} 37 \mathrm{C} /+}$ mice was increased with NVP-BGJ398 treatment from day 9 until the end of the treatment in comparison with the control treatment $(+14.9 \%$ at day $9,+26.5 \%$, at day 16$)$ (Figure $5 \mathrm{~A})$.

Coronal and sagittal $\mathrm{x}$-ray analyses of the axial skeleton did not reveal obvious scoliosis and kyphosis in Fgfr $3^{\mathrm{Y} 367 \mathrm{C} /+}$ mice at 2 weeks of age. In order to assess differences in the size of the axial skeleton, we decided to study lumbar vertebral bodies, which are usually affected in $\mathrm{ACH}$. On $\mathrm{x}$-rays and $\mu \mathrm{CT}$, we observed that lum- 

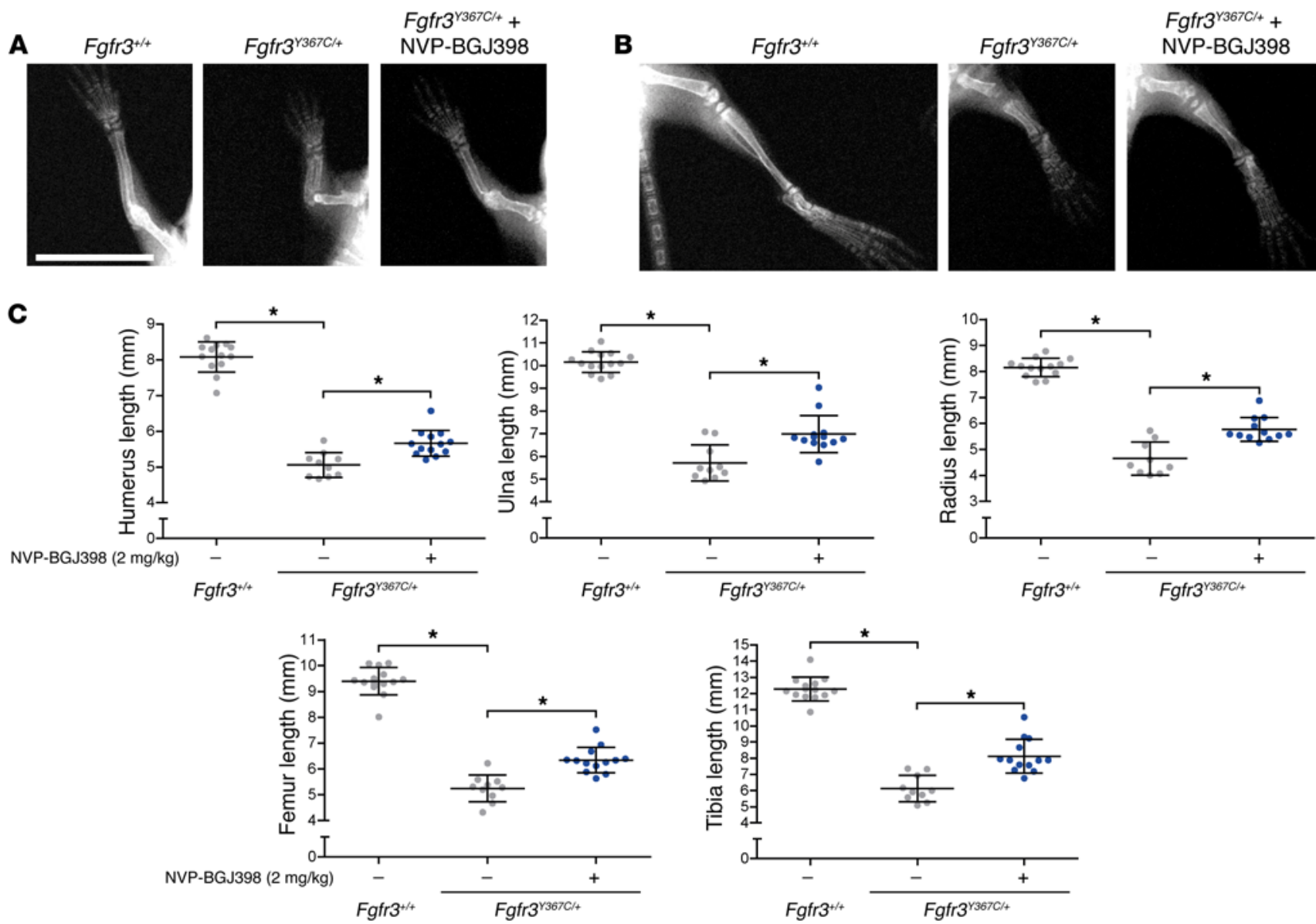

D

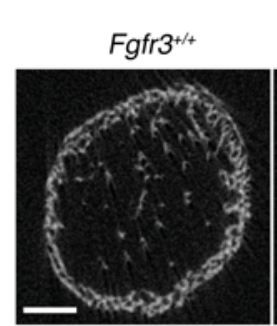

E

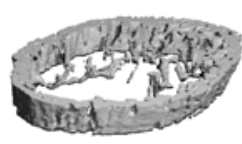

Fgfr3 $^{\text {r } 367 \mathrm{Cl}+\mathrm{H}}$
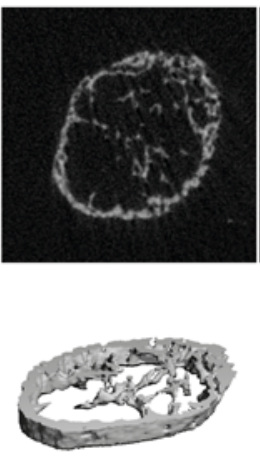

$\mathrm{Fgfr}^{\mathrm{Y} 367 \mathrm{Cl} / 4}+$ NVP-BGJ398
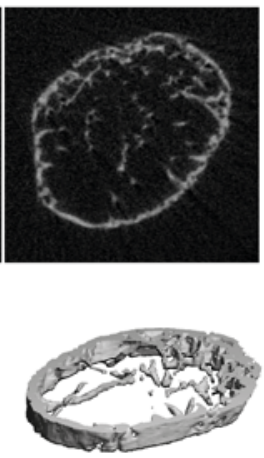

$\mathbf{F}$

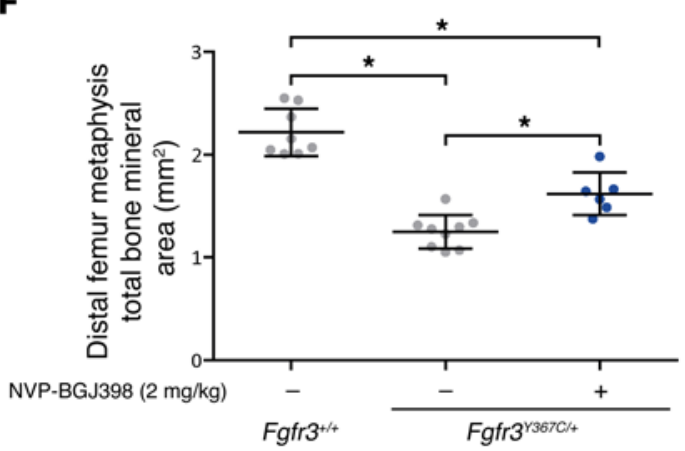

Figure 3. NVP-BGJ398 improves growth of the appendicular skeleton in Fgfr3 ${ }^{2367 / /+}$ mice. (A) Radiograph of $\mathrm{Fgfr}^{+/+}$and treated and untreated $\mathrm{Fgfr}^{\mathrm{Y} 367 \mathrm{Cl} /}$ forelimbs. Scale bar: $1 \mathrm{~cm}$. (B) Radiograph of $\mathrm{Fgfr}^{+/+}$and treated and untreated $\mathrm{Fgfr} \mathrm{F}^{\mathrm{r} 36 \mathrm{Cl} /+}$ hind limbs. (C) Lengths of femur, tibia, humerus, ulna, and radius ( $\mathrm{Fffr}^{+/+}, n=13-14$; untreated $\mathrm{Fgfr}^{\mathrm{Y} 367 \mathrm{C} /+}, n=9-10$; treated $\mathrm{Fgfr} 3^{\mathrm{Y} 367 \mathrm{C} /+}, n=12-13$ ). ${ }^{*} P<0.05$, 1-way ANOVA. (D) $2 \mathrm{D} \mu \mathrm{CT}$ of the distal femur metaphysis cross-sectional area. Scale bar: $400 \mu \mathrm{m}$. (E) 3D $\mu \mathrm{CT}$ of the distal femur metaphysis cross-sectional area. Scale bar: $400 \mu \mathrm{m}$. (F) Total bone mineral area in the distal femur metaphysis ( $F g f \mathrm{fr}^{+/+}, n=8$; untreated $\mathrm{Fgfr} 3^{\mathrm{Y} 367 \mathrm{C} /+}, n=8$; treated $\mathrm{Fgfr} 3^{\mathrm{r} 367 \mathrm{Cl} /+}, n=6$ ). ${ }^{*} P<0.05$, 1-way ANOVA. All data are from animals treated with protocol 1 (16 days old). Data are expressed as mean \pm SD.

bar pedicles were shorter (-62.4\%) in $\mathrm{Fgfr} 3^{\mathrm{Y} 367 \mathrm{C} /+}$ mice compared with $\mathrm{Fgfr}^{+/+}$mice. After treatment with NVP-BGJ398 in Fgfr3 ${ }^{\mathrm{Y} 367 \mathrm{C} /+}$ mice, the lumbar pedicles were greater in size than with the control treatment (+21.8\%) (Figure 5, B and C, and Supplemental Figure 2A). We noted a lower size of the L4-L6 segment in Fgfr $3^{\mathrm{Y3} 67 \mathrm{C} /+}$ compared with $\mathrm{Fgfr}^{+/+}$mice (-29\%), and after 15 days of treatment with NVP-BGJ398, the size was greater than with the control treatment (+12.1\%) (Figure 5D and Supplemental Figure 2A).

To complete these analyses, we focused on IVDs, where FGFR3 is expressed (Supplemental Figure 2B). The IVD contains the cartilage endplate (CEP) and fibrocartilaginous tissues, including the annulus fibrosus (AF) and the nucleus pulposus 
A


B

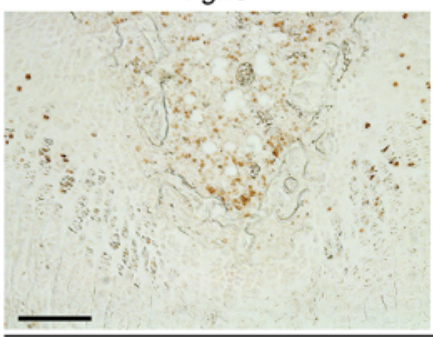

$\mathrm{Fgfr}^{\mathrm{r} 367 \mathrm{Cl}+\mathrm{H}}$


$\mathrm{Fgfr}^{\mathrm{Y} 367 \mathrm{C} / 4}+$ NVP-BGJ398
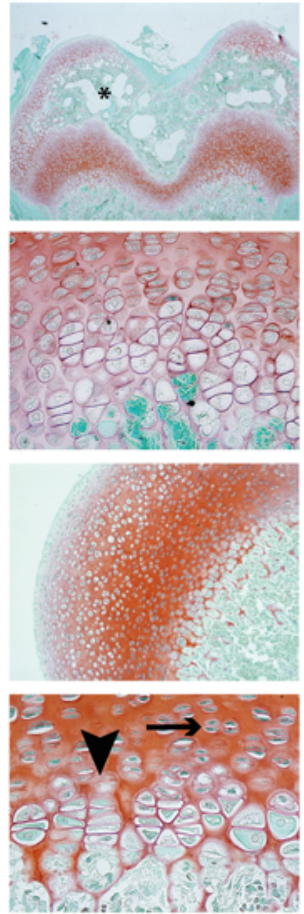

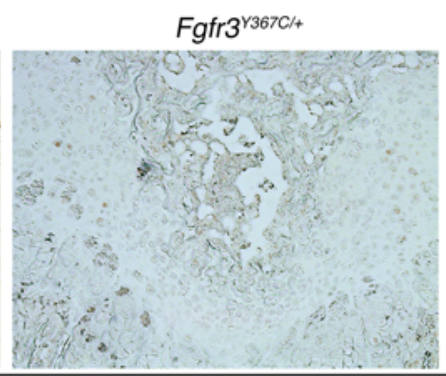

Fgfr $^{\mathrm{ra67C/}+}+$ NVP-BGJ398

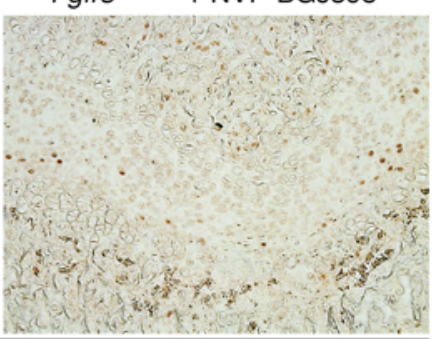

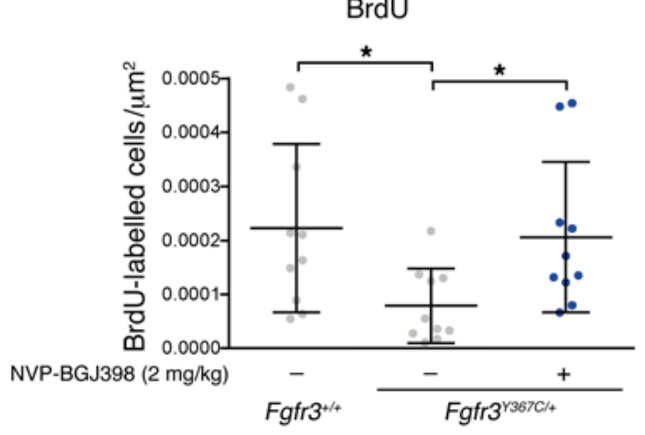

C



Figure 4. NVP-BGJ398 improves chondrocyte differentiation and proliferation in growth plate. (A) Safranin 0 (SO) staining on femur from $\mathrm{Fgfr}^{+/+}$and untreated or treated $\mathrm{Fgfr}^{\mathrm{Y} 367 \mathrm{C} /+}$ mice. Scale bars: $100 \mu \mathrm{m}$. Asterisks show secondary ossification centers $\left(\mathrm{Fgfr}^{+/+}\right.$ and treated $\mathrm{Fgfr}^{\mathrm{Y} 36 \mathrm{CC} / \mathrm{+}}$ have these centers more developed compared with $\mathrm{FgFr}^{\mathrm{r} 36 \mathrm{CT} /+}$ vehicle). Arrowhead highlights appearance of columnar hypertrophic chondrocytes, while arrow indicates flattening of prehypertrophic cells in $\mathrm{Fgfr}^{\mathrm{Y} 366 \mathrm{Cl} /+}$ treated mice. (B) BrdU immunohistology on distal femur growth plates from $\mathrm{FgFr}^{+/+}$and untreated or treated $\mathrm{Fgfr}^{\mathrm{Y} 367 \mathrm{C} / \mathrm{t}}$. Quantification of cell proliferation (BrdU-labeled cells/ $\left.\mu \mathrm{m}^{2}\right)\left(n=10\right.$ per group). ${ }^{*} P<0.05$, 1-way ANOVA. Scale bar: $100 \mu \mathrm{m}$. (C) Immunohistochemistry for $\mathrm{Col} X$ on femur from $\mathrm{Fgfr}^{+/+}$and untreated or treated $\mathrm{Fgfr}^{\mathrm{r} 367 \mathrm{Cl} /+}$. Scale bar: 100 $\mu \mathrm{m}$. Images shown are representative of $n=6$ animals per group. All data are from animals treated with protocol 1 (16 days old). Data are expressed as mean $\pm \mathrm{SD}$. 

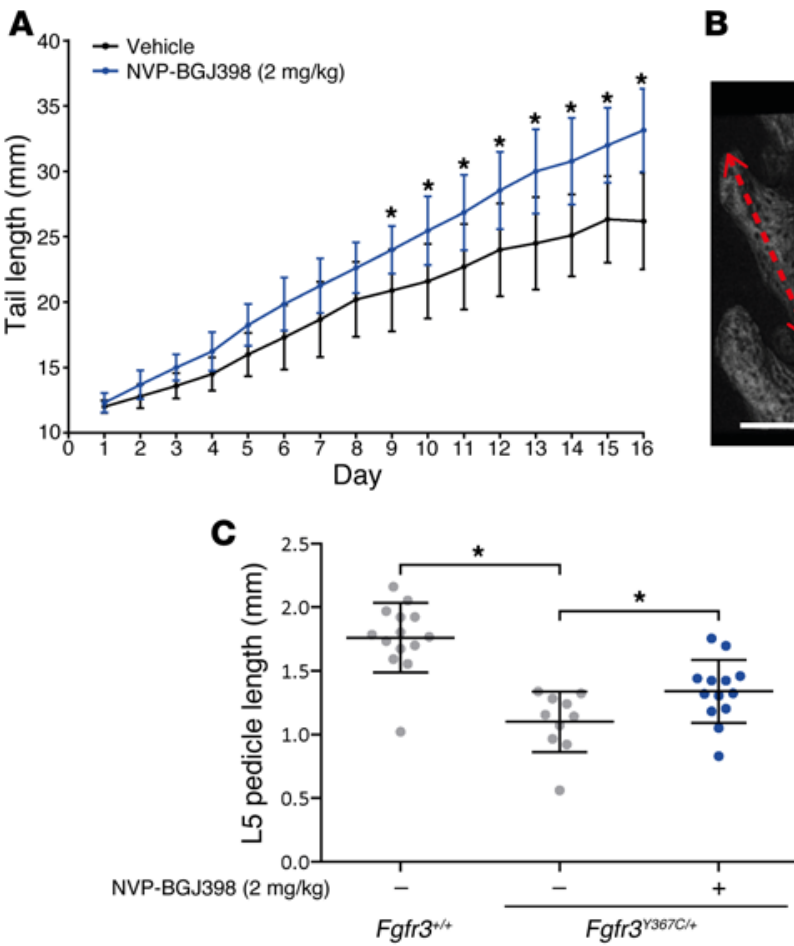

B



$\mathrm{Fgfr}^{\mathrm{r} 367 \mathrm{Cl} / \mathrm{H}}$

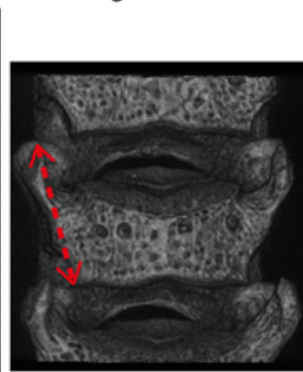

$\mathrm{Fgfr}^{\mathrm{r} 367 \mathrm{Cl} /+}+$

NVP-BGJ398

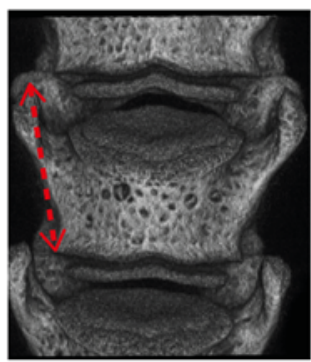

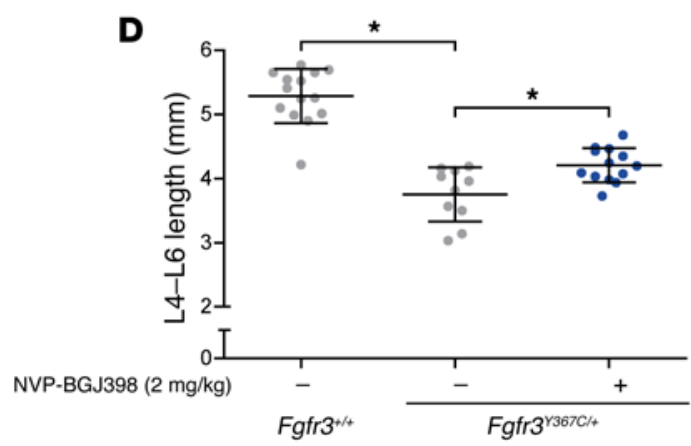

Figure 5. NVP-BGJ398 improves axial skeleton defect of Fgfr3 ${ }^{\mathrm{r} 367 \mathrm{c} /+}$ mice. (A) Tail length from $\mathrm{P} 1$ to $\mathrm{P} 16$ of $\mathrm{Fgfr} 3^{\mathrm{r} 367 \mathrm{C} / \mathrm{+}}$ untreated or treated mice (untreated $\mathrm{Fgfr}^{\mathrm{Y} 367 \mathrm{C} /+}, n=9$; treated $\left.\mathrm{Fgfr} 3^{\mathrm{Y} 367 \mathrm{C} /+}, n=12\right) .{ }^{*} P<0.05$, Mann-Whitney $U$ test. (B) $3 \mathrm{D} \mu \mathrm{CT}$ scan of Fgfr ${ }^{+/+}$and treated and untreated Fgfr $3^{\mathrm{Y} 367 \mathrm{C} /+}$ mice. Red arrows show landmarks used to measure L5 pedicle lengths. Scale bar: $1 \mathrm{~mm}$ (frontal view). (C) L5 pedicle length of Fgfr $3^{+/+}$and treated and untreated

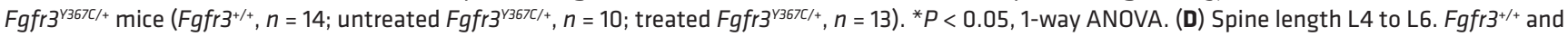
treated and untreated Fgfr $3^{\mathrm{Y} 367 \mathrm{C} /+}$ mice $\left(\mathrm{Fgfr}^{+/+}, n=14\right.$; untreated $\mathrm{Fgfr} 3^{\mathrm{Y} 367 \mathrm{C} /+}, n=10$; treated $\left.\mathrm{Fgfr} 3^{\mathrm{Y} 367 \mathrm{C} /+}, n=13\right)$. ${ }^{*} P<0.05,1-$ way ANOVA. All data are from animals treated with protocol 1 (16 days old). Data are expressed as mean \pm SD.

(NP) (31). The NP is a gelatinous tissue located in the center of the IVD surrounded by the lamellar structured AF. First of all, we observed a lower width $(-52.6 \%)$ and a greater length $(+54.2 \%)$ of the NP in Fgfr $3^{\mathrm{Y367C} /+}$ mice compared with $\mathrm{Fgfr} 3^{+/+}$mice at 16 days (Figure 6, A and B). These defects were significantly ameliorated by NVP-BGJ398 treatment compared with control treatment for both the width $(+73.3 \%)$ and length $(-17.1 \%)$ in $\mathrm{Fg} f \mathrm{r}^{\mathrm{Y} 367 \mathrm{C} /+}$ mice. In order to analyze the AF extracellular matrix (ECM), we studied Col I and II expression. The cartilaginous area (Col II) corresponds to the inner $\mathrm{AF}$ (IAF), and the fibrous area (Col I) forms the outer AF (OAF) (31). Interestingly, we observed for what we believe is the first time that the length of the IAF was higher in Fgfr $3^{\mathrm{Y367C} /+}$ mice $(+72.4 \%)$ than in $\mathrm{Fgfr}^{+/+}$mice (Figure $6 \mathrm{C}$ and Supplemental Figure 2B). This IAF phenotype was significantly ameliorated by NVP-BGJ398 treatment compared with control treatment $(-60 \%)$. As a consequence, the IAF/OAF ratio was also modified with the treatment.

In addition, we observed that the size of the CEP was lower in

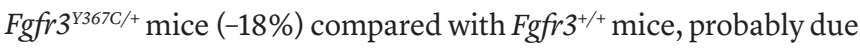
to defective hypertrophic-chondrocyte differentiation (Supplemental Figure 3, A and B). This CEP phenotype was significantly ameliorated by NVP-BGJ398 treatment compared with control treatment (+29.3\%) (Supplemental Figure 3, A and B).

Taking these data together, we demonstrate here that 15 days of NVP-BGJ398 treatment corrected the size of L4-L6 and pedicles and modified collagen expression in the IVD. These data suggest a possible improvement of the ACH spinal stenosis phenotype with treatment.

NVP-BGJ398 improves the growth of the craniofacial skeleton in Fgfr $3^{\mathrm{Y} 367 \mathrm{C} /+}$ mice. The cranial base is severely affected in humans with $\mathrm{ACH}$ and in $\mathrm{Fg} f \mathrm{~F}^{\mathrm{Y} 367 \mathrm{C} /{ }^{+}}$mice and hence contributes greatly to the craniofacial phenotype (28).

Therefore, we assessed whether early treatment with NVPBGJ398 could correct the cartilage defects of the skull base and thus prevent the premature loss of synchondroses. Imaging of the skull using $\mu \mathrm{CT}$ revealed that after 2 weeks of NVP-BGJ398 treatment compared with control treatment, the brachycephalic appearance of $\mathrm{Fg} f \mathrm{r}^{\mathrm{Y} 367 \mathrm{C} /{ }^{+}}$mice was less obvious because the anterior-posterior length of the skull was greater (+5.9\%) (Figure 7A). In addition, we observed that the size of nasal-bone length was lower in $\mathrm{Fg} f \mathrm{r}^{\mathrm{Y} 367 \mathrm{C} /+}$ mice (-33.8\%) than in Fgfr3 $3^{+/+}$mice. This nasal-bone phenotype was significantly ameliorated by NVP-BGJ398 treatment compared with control treatment $(+20.45 \%)$ (Figure 7A). NVP-BGJ398 treatment partially prevented the loss of 4 synchondroses: the sphenooccipital synchondrosis (SOS), the intersphenoidal synchondrosis (ISS), and the 2 interoccipital synchondroses (IOSs) in Fgfr $3^{\mathrm{Y3} 37 \mathrm{C} /+}$ mice (Figure 7, A and B). The efficacy of the NVP-BGJ398 treatment was more prominent on the IOSs (all treated mice had at least one IOS active) than on the SOS and ISS (Table 2).

The size of the FM is much smaller in $\mathrm{ACH}$ patients and Fgfr $3^{\mathrm{Y} 367 \mathrm{C} /+}$ mice, causing cervicomedullary compression (28). In Fgfr $3^{\mathrm{Y} 367 \mathrm{C} / \mathrm{+}}$ mice, the size of the FM was significantly higher after 
A
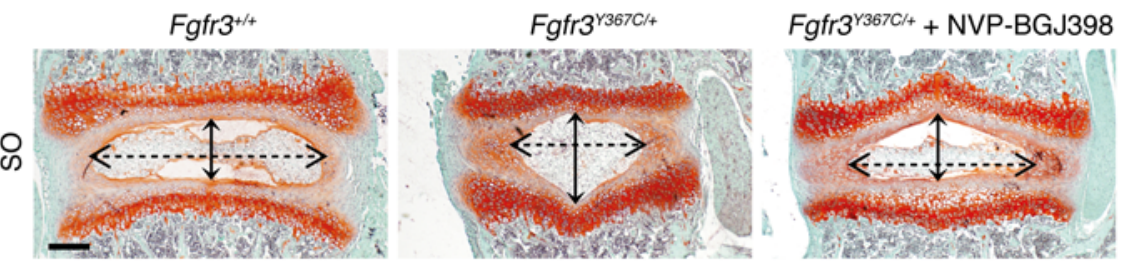

B
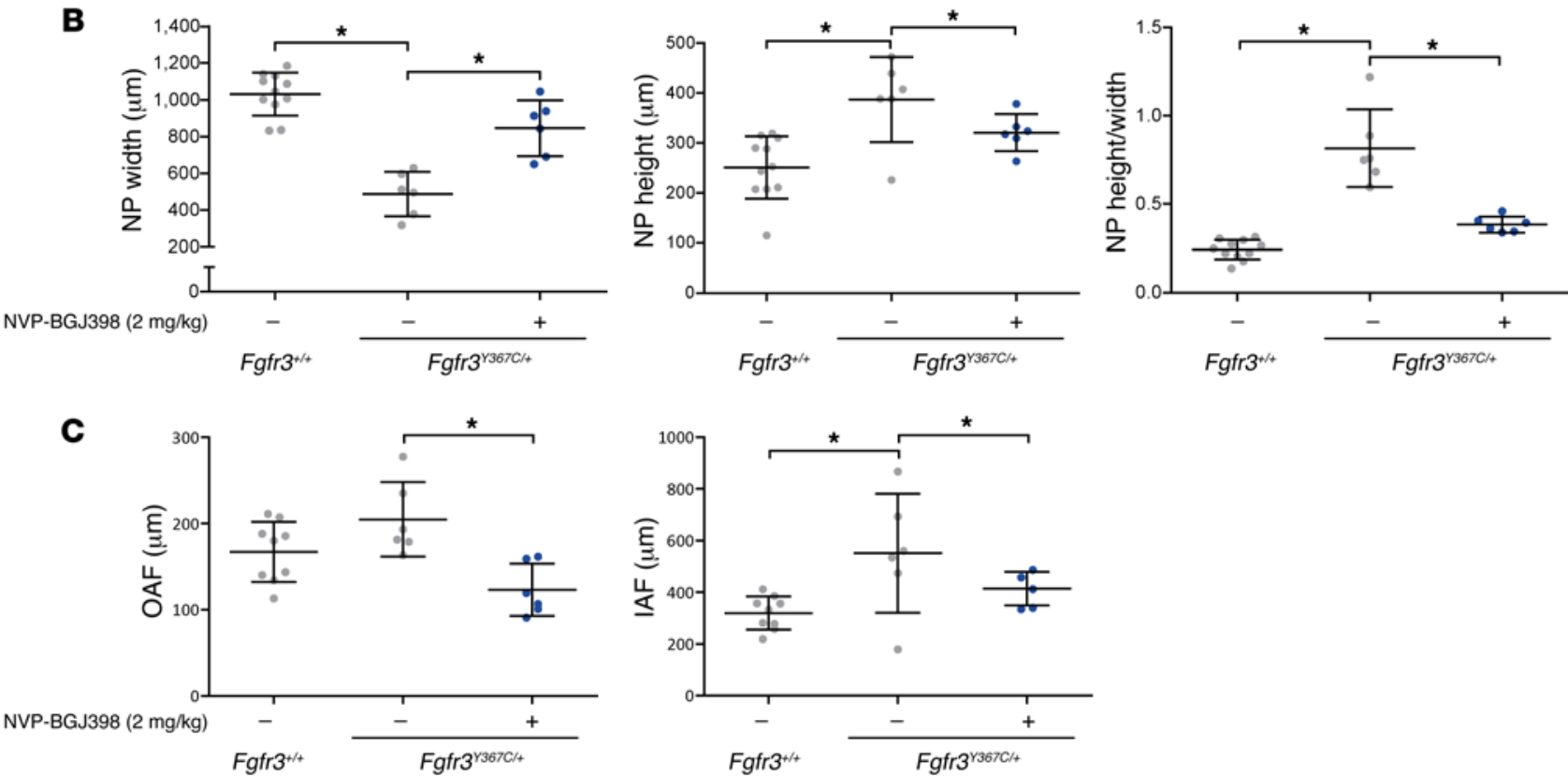

Figure 6. NVP-BGJ398 reduces IVD defects of $\mathrm{Fgfr}^{\mathrm{Y367c/+}}$ mice. (A) Safranin 0 staining on lumbar IVD. Dashed arrow shows NP width; arrow indicates NP height. Scale bar: $200 \mu \mathrm{m}$. (B) NP width $\left(\mathrm{Fgfr}^{+/+}, n=11\right.$; untreated $F g \mathrm{fr}^{\mathrm{r} 367 \mathrm{C} /+}, n=6$; treated $\left.\mathrm{Fgfr}^{\mathrm{r} 367 \mathrm{C} /+}, n=6\right)$. Height and ratio between height

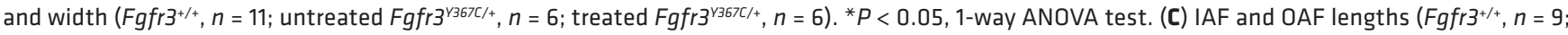
untreated $\mathrm{Fgfr}^{\mathrm{r} 367 \mathrm{Cl} /+}, n=6$; treated $\mathrm{Fgfr}^{\mathrm{Y} 367 \mathrm{C} /+}, n=6$ ). ${ }^{*} P<0.05$, 1-way ANOVA. All data are from animals treated with protocol 1 (16 days old). Data are expressed as mean $\pm \mathrm{SD}$.

NVP-BGJ398 treatment (area, $+16.8 \%$; transversal length, $+15.8 \%$; and sagittal length, $+7.6 \%$ as assessed by $\mu \mathrm{CT}$ ) (Figure 8 , A and B). The rescue of the synchondroses phenotype presumably played a role in the amelioration of the FM phenotype.

These data indicate an impact of FGFR3 on both mesenchymal (synchondroses) and neural crest-derived osteoblasts (nasal bone) and suggest an important role of FGFR3 on both intramembranous and endochondral ossification processes.

NVP-BGJ398 rescues defective FGFR3 signaling. FGFR3 is expressed in proliferative and prehypertrophic zones of the growth plate and modulates both proliferation and differentiation of the chondrocytes (32). The activating mutation stabilizes the receptor in cells, as demonstrated by the high expression of the receptor in the growth plate. The treatment of NVP-BGJ398 had a beneficial effect on the turnover of the receptor and lowered its expression in chondrocytes (Supplemental Figure 4A). In our Fgfr $3^{\mathrm{Y367C/+}}$ mice, as expected, another tyrosine kinase, FGFR1, was expressed in the hypertrophic zone of the growth plate, and its expression was not modified with NVP-BGJ398 treatment (Supplemental Figure 4B).

FGFR3 negatively regulates chondrocyte proliferation and differentiation via several signaling pathways. The 2 principal signaling pathways are the MAPK pathway, which regulates matrix production and chondrocyte differentiation, and the STAT1 pathway, which controls proliferation (32). The FGFR3 canonical downstream MAPK signaling pathway is more active in FGFR3-related disorders $(33,34)$. Consistent with decreased FGFR3 phosphorylation, the activation of MAPK and PLC $\gamma$ pathways was reduced with NVP-BGJ398 dosing in HEK293-Vnr cells and human chondrocytes transiently transfected with constructs encoding activation mutants of FGFR3 (Supplemental Figure 5, A and B). These results were confirmed using human immortalized ACH (p.Gly380Arg/+) and TD (p.Ser249Cys/+) chondrocytes (ref. 25 and Supplemental Figure $5 \mathrm{C}$ ) and using human $(\mathrm{ACH}$, control) and mouse primary chondrocytes (Figure 9, A and B). With these cell cultures, we also observed a NVP-BGJ398 dose-dependent decrease in the level of phosphorylated ERK1/2 (Supplemental Figure 5C).

High levels of phosphorylated ERK1/2 were observed in Fgfr $3^{\mathrm{Y367C/+}}$ chondrocyte cultures and in the growth plate of Fgfr $3^{\mathrm{Y} 367 \mathrm{C} /{ }^{+}}$mice in vivo, thus confirming the constitutive activation of the MAPK pathway in those mice (Figure 9C). Interestingly, ERK1/2 phosphorylation was undetectable in NVP-BGJ398-treated chondrocyte cultures, and ERK1/2 phosphorylation was lower in growth-plate cartilage after NVP-BGJ398 treatment compared with control treatment in $\mathrm{Fg} f \mathrm{~F}^{\mathrm{Y3} 37 \mathrm{C} / \mathrm{+}}$ mice (Figure 9, A-C, and Supplemental Figure 5, A-C). These data show that NVP-BGJ398 inhibited FGFR3 activity in a RAS-ERK-dependent fashion. 

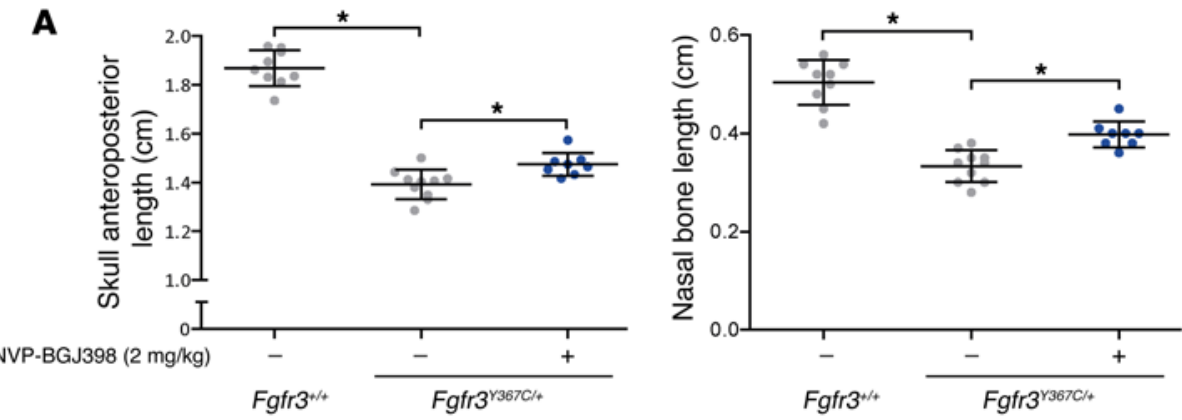

B
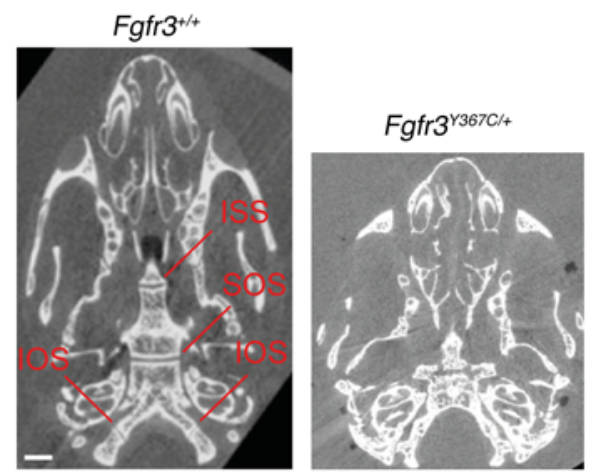

$\mathrm{Fgfr}^{\mathrm{r} 367 \mathrm{Cl} / 4}+$

NVP-BGJ398

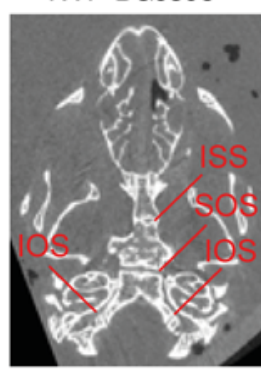

Fgfr3 $^{+/ 4}$
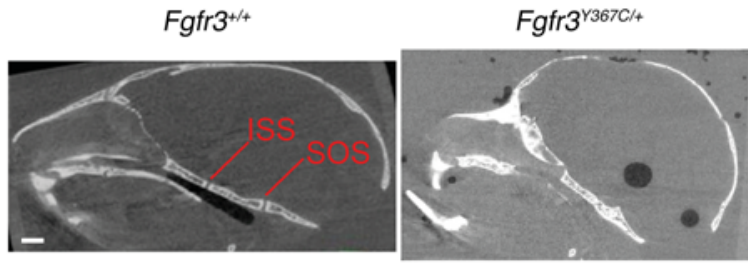

Fgfr $^{\text {r367C/4 }}+$ NVP-BGJ398



Figure 7. NVP-BCJ398 improves growth of the craniofacial skeleton in $\mathrm{FgFr}^{\mathrm{r} 367 \mathrm{C} /+}$ mice. (A) Skull anteroposterior length and nasal bone length $\left(F g \mathrm{Fr}^{+/+}, n=9\right.$; untreated

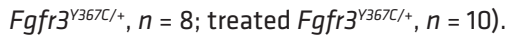
${ }^{*} P<0.05,1$-way ANOVA. Data are expressed as mean $\pm \mathrm{SD}$. (B) $2 \mathrm{D} \mu \mathrm{CT}$ scan of $\mathrm{Fgfr}^{+/+}$ and treated and untreated $\mathrm{Fgfr}^{\mathrm{Y3} 36 \mathrm{C} / \mathrm{+}}$ mouse skulls shows the presence and loss of synchondroses. Scale bar: $1 \mathrm{~mm}$. All data are from animals treated with protocol 1 (16 days old).
The role of the transcription factor SOX9 in chondrogenic differentiation is well recognized $(35,36)$. Previously, it was reported that activated FGFR3 prevents the downregulation of transcription factor SOX9 in differentiated chondrocytes (11). This mechanism was also observed in $\mathrm{Fg} f \mathrm{~F}^{\mathrm{Y} 367 \mathrm{C} /{ }^{+}}$mice where the high expression of SOX9 in the prehypertrophic chondrocytes was lowered with NVP-BGJ398 treatment (Figure 9D). Also, the downregulation of SOX9 correlated with the modification of the size and the shape of hypertrophic chondrocytes (Figure 4, A and C).

In FGFR3-related disorders, it has been demonstrated that the STAT1 pathway regulates chondrocyte proliferation $(37,38)$. In the $\mathrm{Fgfr}^{\mathrm{Y} 36 \mathrm{CC} / \mathrm{+}}$ growth plate, the level of phosphorylated STAT1 is higher than in $\mathrm{Fgfr}^{+/+}$mice, and the level of phosphorylated STAT1 is lowered by NVP-BGJ398 treatment (Supplemental Figure 5D). Hence, these data provide an underlying molecular explanation for the higher rate of chondrocyte proliferation with NVP-BGJ398 treatment in $\mathrm{Fg} f \mathrm{Fr}^{\mathrm{Y} 367 \mathrm{C} /+}$ mice, as shown with BrdU data (Figure $4 \mathrm{~B}$ ).

Overall, the data suggest that NVP-BGJ398 treatment in $\mathrm{Fgfr}^{\mathrm{Y} 36 \mathrm{CC} /+}$ mice restores the activity of FGFR3 downstream-signaling pathways to that of levels observed in $\mathrm{Fgfr}^{+/+}$mice.

Effect of timing and type of treatment on the improvement of bone growth. Bone elongation relies on an active process controlled by proliferation and differentiation of chondrocytes within the growth plate. In humans, this process comes to a halt at puberty and corresponds to the disappearance of the growth plate. Therefore, in ACH patients, treatment effectiveness may be better if the treatment commences before puberty. For this reason, we chose to treat $\mathrm{Fg} f \mathrm{rr}^{\mathrm{Y} 36 \mathrm{CC} / \mathrm{+}}$ mice from day 1 for 15 days (protocol 1). However, in order to compare the efficacy of NVP-BGJ398 with that shown in previously published data, we also tested a second protocol (protocol 2), similar to the one used for BMN111 (start at day 7 for 10 days) (15). The gain of growth of femurs and tibias was $50 \%$ higher in animals treated earlier and longer with NVP-BGJ398 (from day 1) than those treated from day 7 (Supplemental Figure 6 and Table 3). When NVP-BGJ398 treatment was compared with BMN111 treatment in Fgfr $33^{\mathrm{Y} 36 \mathrm{CC} / \mathrm{+}}$ mice using protocol 2, we observed a greater amelioration of several aspects of the dwarfism pheno-

\section{Table 2. Active synchondroses}

$\begin{array}{lccc} & \mathrm{Fgfr}^{+/+} & \mathrm{Fgfr3}^{\mathrm{r} 367 / /+} & \mathrm{Fgfr3}^{\mathrm{r} 367 / /+}+\text { NVP-BC]398 } \\ \text { ISS } & 100 \%(9 / 9) & 0 \%(0 / 10) & 37.5 \%(3 / 8) \\ \text { SOS } & 100 \%(9 / 9) & 0 \%(0 / 10) & 25 \%(2 / 8) \\ \text { Both IOSs } & 100 \%(9 / 9) & 0 \%(0 / 10) & 75 \%(6 / 8) \\ 1 \text { IOS only } & - & 0 \%(0 / 10) & 25 \%(2 / 8)\end{array}$

Percentage of active synchondroses. All data are from animals treated with protocol 1 (16 days old). 
A
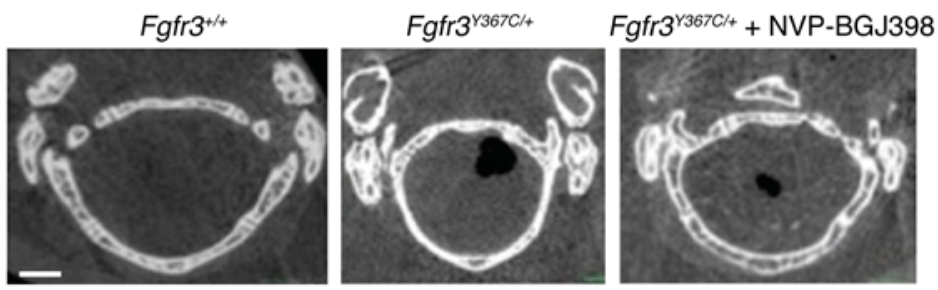

B

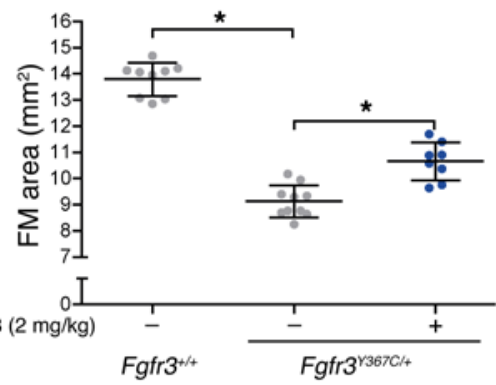

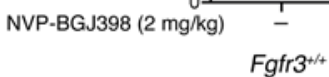

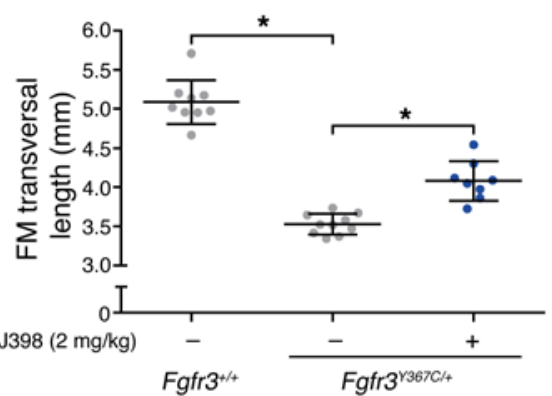

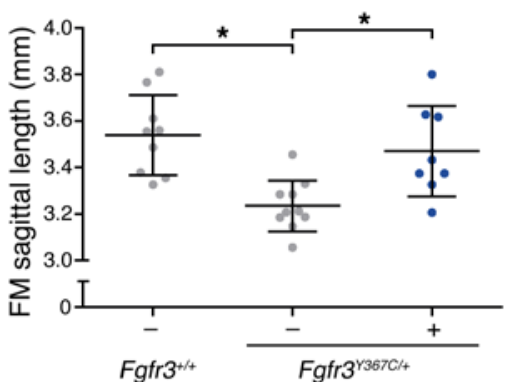



Figure 8. NVP-BGJ398 reduces FM defects in Fgfr $^{\text {rab7C/+ }}$ mice. (A) FM $\mu \mathrm{CT}$ images. Scale bar: $1 \mathrm{~mm}$. (B) FM area, transversal and sagittal length, ratio between FM sagittal and transversal length $\left(\mathrm{Fgfr}^{+/+}, n=9\right.$; untreated $\mathrm{Fgfr}^{\mathrm{Y} 367 \mathrm{C} /+}$, $n=8$; treated Fgfr3 $\left.{ }^{\mathrm{r} 367 \mathrm{C} /+}, n=10\right) .{ }^{*} P<0.05$, 1-way ANOVA test. All data are from animals treated with protocol 1 ( 16 days old). Data are expressed as mean $\pm \mathrm{SD}$. type with NVP-BGJ398 than with BMN111 (femur, tibia, tail, L4-L6) (Supplemental Figure 6, Table 3, and ref. 15). In conclusion, NVP-BGJ398 treatment of Fgfr $3^{\mathrm{Y} 367 \mathrm{C} /+}$ mice appeared more effective when administered earlier postnatally and for a longer period. NVP-BGJ398 treatment also appeared more effective than BMN111 treatment, suggesting that directly targeting FGFR3 with a TKI represents a better approach than targeting FGFR3 downstream-signaling pathways.

\section{Discussion}

Elevated kinase activity of the FGFR3 receptor due to germinal or somatic mutations disrupts several biological functions, as demonstrated in FGFR3-related disorders ( $\mathrm{ACH}, \mathrm{TD}$, hypochondroplasia, Muenke syndrome) $(1,2,39)$ and numerous cancers (bladder cancers and multiple myeloma) (40-42). Hyperactive FGFR3 signaling causes dwarfism, including $\mathrm{ACH}$, which is characterized by anomalies in bone development, and the gain-of-function Fgfr $3^{\mathrm{Y367C/+}}$ mutation can be used to model ACH in mice $(6,28,29$, 43). Conversely, a total impairment of the FGFR3 signaling pathway can cause bone overgrowth, confirming that FGFR3 is a negative regulator of bone growth (5). On a functional level, FGFR activation affects various cell behaviors via the downstream activation of the MAPK intracellular signaling cascade. The MAPK pathway plays an important role in bone development, as demonstrated in MEK1 gain-of-function mice (12) and ERK1 and ERK2 null mice (44), leading to a dwarf or skeletal overgrowth phenotype, respectively. The underlying mechanisms in FGFR3-related disorders suggest that chondrocyte differentiation is regulated by MAPK signaling through the control of SOX9 (32) and chondrocyte proliferation is suppressed by STAT1 activation (12).

One therapeutic strategy to rescue the defective skeletal development caused by FGFR3 gain-of-function mutations is to reduce or counteract the hyperactivity of FGFR3. Among the putative therapeutic approaches for $\mathrm{ACH}$, the use of TKIs seems the most suitable. Although TKIs have been successfully used in cancer (45-47), TKIs have so far not been applied in skeletal disorders. Here, we demonstrate that NVP-BGJ398, a pan-FGFR inhibitor (20), was able to reduce the increased phosphorylation of FGFR3 and the activation of its downstream signaling pathways in vitro, in human and mouse ( $\left.\mathrm{Fg} f \mathrm{r}^{\mathrm{Y} 367 \mathrm{C} /+}\right)$ chondrocyte models of $\mathrm{ACH}$, and to rescue the growth-plate phenotype in vivo in $\mathrm{Fgfr}^{\mathrm{Y3} 67 \mathrm{C} /+}$ mice. We believe the result obtained with NVP-BGJ398 is novel, as previous in vivo experiments using TKIs failed to demonstrate any rescue of the dwarf phenotype (48). Previously, NVP-BGJ398 was tested in animal models for cancers, including hepatocellular carcinoma (24) and malignant rhabdoid tumors (23) as well as FGF23-dependent hypophosphatemic rickets (22). The effective doses administrated in these preclinical studies for cancer were 10 to 100 times higher than the doses used in this present study to correct the dwarfism phenotype. Other therapeutic strategies were explored for ACH, with protocols using soluble FGFR3 (17), statin (18), or meclozine (19) in another mouse model of ACH $\left(F g f r 3^{A c h}\right)$ in which the Fgfr3 transgene with the ACH mutation is expressed under the control of Col2a1 (7). The comparison of those results with the results from our study is made complicated by the differences among the mouse models (genotypes, skeletal 
A
B

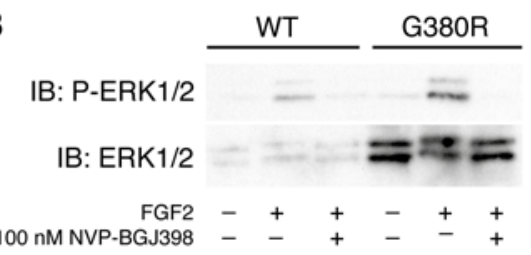

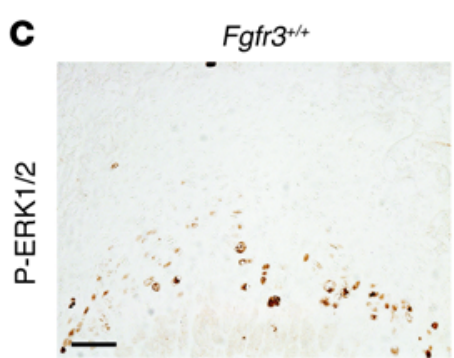

D

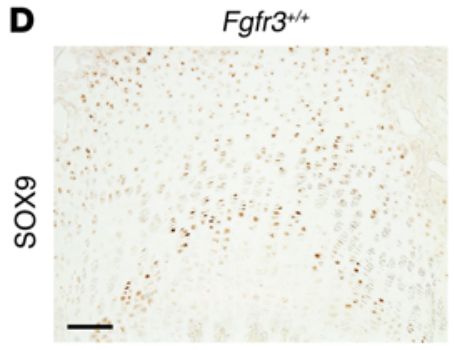

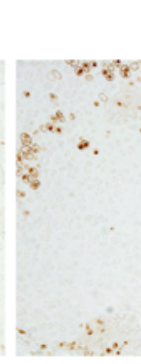

$\mathrm{Fgfr}^{\mathrm{r} 367 \mathrm{C} / \mathrm{t}}$

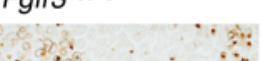

Fgfr' $^{\text {r367C// }}+$ NVP-BGJ398

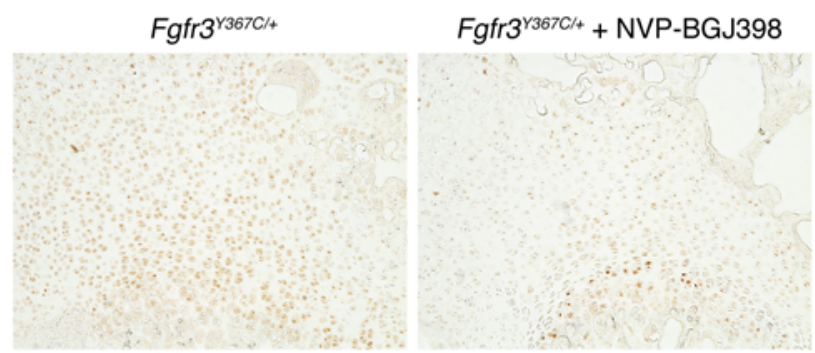

Figure 9. NVP-BGJ398 rescues defective FGFR3 signaling. (A) Phosphorylated ERK1/2 expression in mouse primary chondrocytes ( $\mathrm{Fgr3}^{+/+}$and

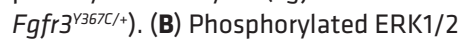
expression in human primary chondrocytes expressing FGFR ${ }^{\mathrm{WT}}$ or the heterozygous mutation G380R (ACH). (C) Immunohistology for phosphorylated ERK1/2 in femur distal growth plate of protocol 1 mice. Scale bar: $100 \mu \mathrm{m}$. Images shown are representative of $n=9$ animals per group. (D) Immunohistology for SOX9 in femur distal growth plate of protocol 1 mice. Scale bar: $100 \mu \mathrm{m}$. Images shown are representative of $n=6$ animals per group. All immunohistological data are from animals treated with protocol 1 (16 days old). Western blots are representative of 3 independent experiments. phenotypes, and FGFR3 expression pattern) (17-19). Interestingly, NVP-BGJ398 treatment for 10 days improved the bone growth 2 to 3 times more than what had been reported for BMN111 (15). NVPBGJ398 $(2 \mathrm{mg} / \mathrm{kg})$ treatment of WT mice did not affect skeletal growth (data not shown), and treatment of $\mathrm{Fg} g \mathrm{rr}^{\mathrm{Y} 36 \mathrm{CC} /+}$ mice did not modify the expression of FGFR1 in the hypertrophic zone of the growth plate. Thus, in this preclinical study, NVP-BGJ398-mediated effects were mainly due to FGFR3 inhibition, with no other gross side effects being observed.

The rescue of the growth-plate disorganization, the defective chondrocyte proliferation, and the delay of differentiation and secondary ossification were remarkable. The disrupted downstream FGFR3 signaling pathways were corrected with the NVPBGJ398 treatment, confirming the key role of ERK1/2, SOX9, and STAT1 signaling during skeletal development (32).

Of major importance, NVP-BGJ398, when applied from birth onwards, increased the size of the reduced FM and inhibited the premature fusion of synchondroses. In addition, the size of the neural crest-derived nasal bone was increased, reflecting that intramembranous ossification is also affected in ACH (28). These treatment-related effects on the skull suggested the potential of correcting facial appearance in ACH patients and, most importantly, the potential of reducing the risks related to the cervicomedullary compression and early death that can occur in $\mathrm{ACH}$ children $(1,49,50)$.

The spine anomalies of children and adults with $\mathrm{ACH}$ are kyphosis at the thoracolumbar junction (51) and spinal stenosis (52), eventually leading to leg paralysis and neurogenic claudica- tion (2). Here, we demonstrate that the axial skeleton was affected in $\mathrm{Fgfr}^{\mathrm{Y} 367 \mathrm{C} /+}$ mice and the size of the lumbar vertebral bodies and pedicles was reduced. In addition, we showed that the 3 components (NF, AF, CEP) of the IVD were affected. One of the findings of this study is that NVP-BGJ398 treatment remarkably corrected the lumbar vertebral body and pedicle size defects and modified the components of the ECM of the IVD. These data demonstrate that overactivation of FGFR3 disturbs cartilage, IVDs, and boneforming lumbar rachis, thus explaining the spinal stenosis, herniated disc, and kyphoscoliosis phenotypes of ACH patients. The positive impact of NVP-BGJ398 treatment is particularly noteworthy in this context: an improvement of axial skeletal development in $\mathrm{ACH}$ could reduce the need for decompressive laminectomy surgery, a procedure required for treating severe spinal stenosis (52).

The duration of the NVP-BGJ398 treatments were probably too short for the amelioration of the defective bone structure of the long bones in $\mathrm{Fgfr} 3^{\mathrm{Y} 367 \mathrm{C} /+}$ mice (43). Longer treatments might be necessary to improve the bone architecture, as demonstrated previously with 2 months of PTH injection in an Fgfr3-related

\section{Table 3. Effect of timing and type of treatment}

$\begin{array}{lcccc}\text { Treatment } & \text { Tail } & \text { Femur } & \text { Tibia } & \text { L4-L6 } \\ \text { NVP-BG]398 } 2 \mathrm{mg} / \mathrm{kg} \text { (protocol 1) } & 26.5 \%^{\mathrm{A}} & 20.9 \%^{\mathrm{A}} & 32.6 \%^{\mathrm{A}} & 12.1 \%{ }^{\mathrm{A}} \\ \text { NVP-BC]398 } 2 \mathrm{mg} / \mathrm{kg} \text { (protocol 2) } & 25.8 \%{ }^{\mathrm{A}} & 12.1 \%^{\mathrm{A}} & 25.5 \%^{\mathrm{A}} & 11.6 \%{ }^{\mathrm{A}}\end{array}$

Gain in length (percentage) for tail, femur, tibia, and L4-L6 of NVP-BGJ398-treated mice compared with vehicle 1 . A best improvement is observed with animals treated at day 1 (protocol 1). The dwarfism improvement is more important with NVP-BGJ398 than with BMN111 (protocol 2 compared with data from ref. 15). ${ }^{A} P<0.05$ by 1 -way ANOVA test. 
dwarf mouse model (16). Because short-term NVP-BGJ398 treatment improved the chondroosseous junction in the long bones of the growing $\mathrm{Fg} f \mathrm{r}^{\mathrm{Y3} 36 \mathrm{C} / \mathrm{+}}$ mice, there is potential that longer NVPBGJ398 treatments could lead to a secondary positive effect on the resulting bone structure.

The different skeletal phenotypes and molecular pathways evaluated in our study provide a wide range of markers that can be monitored for further optimization of dosing schedules of TKI in addition to prolongation, such as reductions in dose quantity or frequency (e.g., intermittent injections every 2 or 3 days).

In summary, we have shown that NVP-BGJ398 inhibits FGFR3 and its downstream signaling pathways, which are overactive in cartilage in ACH. As a consequence, NVP-BGJ398 rescues the endochondral and membranous ossification processes in a mouse model of ACH. Our results provide a rationale for targeting FGFR3 with a specific TKI for the treatment of children with $\mathrm{ACH}$.

\section{Methods}

Transient transfections of cDNA FGFR3 constructs. Human control chondrocyte lines (25) and human embryonic kidney (HEK) cells (26) at $80 \%-90 \%$ confluence were transiently transfected with FGFR3 human constructs (FGFR3 ${ }^{\mathrm{WT}}$, FGFR3 ${ }^{\mathrm{G} 380 \mathrm{R}}{ }$, FGFR3 ${ }^{\mathrm{Y} 373 \mathrm{C}}$, FGFR3 ${ }^{\mathrm{K} 650 \mathrm{E}}$, FGFR $3^{\mathrm{K} 650 \mathrm{M}}$ ) obtained as previously reported (26) using JetPrime (Polyplus-transfection) following the manufacturer's instructions. Transfected cells were incubated with NVP-BGJ398 (Novartis Basel, ref. 20) at concentrations of $100 \mathrm{nM}, 1 \mathrm{nM}$, or $10 \mu \mathrm{M}$ overnight. Transfected cells were lysed in RIPA buffer (50 mM Tris- $\mathrm{HCl} \mathrm{pH}$ 7.6, 150 $\mathrm{mM} \mathrm{NaCl}, 0.5 \% \mathrm{NP} 40$, and $0.25 \%$ sodium deoxycholate, supplemented with protease and phosphatase inhibitors; Roche). Immunoprecipitations were performed by incubating $3 \mu \mathrm{l}$ rabbit anti-FGFR3 (SigmaAldrich F0425) $/ 500 \mu \mathrm{g}$ protein with protein A-agarose (Roche).

Primary and immortalized human chondrocytes and mouse chondrocytes cultures. Primary and immortalized mutant cells were obtained as previously described (25). The protocol used for mouse chondrocytes was previously reported (24). Human and mouse cells were incubated with NVP-BGJ398 (1, 10, 50, 100, 250, and $500 \mathrm{nM})$ overnight.

Immunoblotting. Whole-cell lysates and immunoprecipitated proteins were subjected to NuPAGE $4 \%-12 \%$ bis-tris acrylamide gels (Life Technologies). Blots were probed with antibodies using standard protocols: anti-FGFR3 polyclonal antibody (Sigma-Aldrich F0425; 1:1,000 dilution), anti-phospho-tyrosine P-Tyr-100 monoclonal antibody (Cell Signaling catalog 9411; 1:1,000 dilution), anti-phosphoERK1/2 monoclonal antibody (Cell Signaling catalog 4370; 1:1,000 dilution), anti-ERK1/2 polyclonal antibody (Sigma-Aldrich M5670; 1:1000 dilution), anti-phospho-PLC $\gamma$ polyclonal antibody (Cell Signaling catalog 2821; 1:1,000 dilution), and anti-PLC $\gamma$ polyclonal antibody (Cell Signaling catalog 2822; 1:1,000 dilution).

Mouse model and drug treatment. Fgfr $3^{\mathrm{Y} 367 \mathrm{C} /+}$ mice were described previously (29). All mice were on a C57BL/6 background. Cartilage and bone analyses were performed in 16-day-old mice. Protocol 1 was as follows: $\mathrm{Fg} f \mathrm{~F}^{\mathrm{Y367C/+}}$ mice were 1 day old at treatment initiation and received daily subcutaneous administrations of NVP-BGJ398 for 15 days ( $2 \mathrm{mg} / \mathrm{kg}$ body weight) or vehicle (HCl $3.5 \mathrm{mM}$, DMSO 5\%). Treated and control mice received an intraperitoneal BrdU (Invitrogen) injection ( $1 \mathrm{ml}$ per $100 \mathrm{~g}$ body) 2 hours before sacrifice. Long bones were measured by caliper (VWRi819-0013, VWR International), while vertebrae measures were determined from radiograph with ImageJ (https://imagej.nih.gov/ij/). Protocol 2 was as follows: Fgfr $3^{\mathrm{Y} 367 \mathrm{C} /+}$ mice were 7 days old at treatment initiation and received daily subcutaneous administrations of NVP-BGJ398 (2 mg/kg body weight) or vehicle ( $\mathrm{HCl} 3.5 \mathrm{mM}$, DMSO 5\%) for 10 days; this protocol is similar to the BMN111 protocol previously described (15).

Genotyping. Genomic DNA was isolated from tail tips by proteinase $\mathrm{K}$ digestion and extracted with NucleoSpin Tissue (MachereyNagel) according to the manufacturer's instructions. PCR was performed using primers as previously described (29).

Femoral culture system. Ex vivo femur cultures were conducted as described previously (30). Right femur was cultured with NVPBGJ398 at a concentration of $10-100 \mathrm{nM}$ to $1 \mu \mathrm{M}$ and compared with the untreated left femur. The bone length was measured at the beginning (before treatment) and at the end of time course. Each experiment was repeated at least 5 times. Images were captured with an Olympus SZX12 stereo microscope. The size of the femur was measured using cellSens software (Olympus).

Calvarial culture system. Ex vivo calvarial cultures were conducted as described previously (28). Calvaria (E18.5) were placed in 24 -well plates on top of $250 \mu \mathrm{l}$ of Matrigel (BD Biosciences) previously placed at the bottom of the well. Calvaria were cultured in $\alpha$-MEM (Gibco, Life Technologies) supplemented with 10\% FBS (Gibco, Life Technologies), $100 \mu \mathrm{g} / \mathrm{ml}$ ascorbic acid (Sigma-Aldrich), and 1\% penicillin/streptomycin (Gibco, Life Technologies) and NVP-BGJ398 at $100 \mathrm{nM}$ over 14 days. Images were captured with an Olympus SZX12 stereo microscope. The size of the calvaria defect was measured using ImageJ software.

Histological and immunohistochemical analyses. Fetal femur explants, long bones (femurs, tibias), and L4-L6 vertebrae were fixed in $4 \%$ paraformaldehyde, decalcified with EDTA $0.4 \mathrm{M}$, and embedded in paraffin. Serial sections of $5 \mu \mathrm{m}$ were stained with H\&E and safranin O. For immunohistochemistry, sections were labeled with antibodies against Ki67 (monoclonal antibody, Abcam ab92353; 1:3,000 dilution), Col X (BIOCYC, N.2031501005; 1:50 dilution), CD34 (monoclonal antibody, Abcam ab8158; 1:100 dilution) Col I (polyclonal antibody, Novotec, catalog 20151; 1:1,000 dilution), Col II (polyclonal antibody, Novotec, catalog 20251; 1:1,000 dilution), SOX9 (polyclonal antibody, Santa Cruz Biotechnology Inc., catalog D0609; dilution 1:75), phospho-ERK1/2 (monoclonal antibody, Cell Signaling, catalog 4370; 1:100 dilution), phospho-Stat 1 (polyclonal antibody, Abcam, catalog ab119331; 1:200 dilution), FGFR1 (polyclonal antibody, Abcam, catalog ab63601; 1:75 dilution), and FGFR3 (polyclonal antibody, Sigma-Aldrich, catalog F0425; 1:250 dilution) using the Dako Envision Kit. Proliferation was analyzed with the BrdU Staining Kit (Life Technologies). Images were captured with an Olympus PD70-IX2-UCB microscope and cellSens software. Labeled cells were counted using ImageJ software.

$X$-rays and CT scanner. The whole skeletons of the mice were radiographed using Faxitron (MX-20). $\mu \mathrm{CT}$ analyses were performed using a $\mu \mathrm{CT} 40$ Scanco vivaCT42 (Scanco Medical) instrument and the following settings: integration time, $300 \mathrm{~ms}$ (skull) or $175 \mathrm{~ms}$ (femur); $45 \mathrm{E}(\mathrm{kVp}) ; 177 \mu \mathrm{A}$. For determination of femoral structural parameters, a segmentation threshold of 270 was applied and a Gaussian filter ( $\sigma=0.7$, support of 1 voxel) was used to suppress the noise. The evaluated volume was proportional to the femoral length, as measured on plain radiographs using a specimen radiography system (Faxitron LX-60), and corresponded to an average of $142 \mu \mathrm{m}$ (metaphysis) or 
$120 \mu \mathrm{m}$ (diaphysis) for vehicle-treated and $169 \mu \mathrm{m}$ (metaphysis) or 143 $\mu \mathrm{m}$ (diaphysis) for compound-treated $\mathrm{Fg} f \mathrm{~F}^{\mathrm{Y367C/+}}$ mice.

Statistics. Differences between experimental groups were assessed using ANOVA with Tukey's post hoc test or Mann-Whitney $U$ test. The significance threshold was set at $P \leq 0.05$. Statistical analyses were performed using GraphPad PRISM (v5.03). All values are shown as mean \pm SD.

Study approval. Experimental animal procedures and protocols were approved by the French Animal Care and Use Committee.

\section{Author contributions}

DKE, ED, IK, AM, and LLM designed the research. DKE, ED, CBL, NK, CLG, LM, and MBD performed the experiments. DKE, IK, FDR, and MBD analyzed the scanners. PB, FB, and DGP analyzed NVP-BGJ398 activity. DKE prepared the figures. DKE, IK, MK, MBD, and LLM wrote the manuscript.

\section{Acknowledgments}

This program received a state subsidy managed by the National Research Agency under the Investments for the Future program bearing the reference ANR-10-IHU-01 and the ANR-ATAK 2013 program. Some of the work presented here was funded by the European Community's Seventh Framework Programme under grant agreement no. 602300 (Sybil). We are grateful to the Association des Personnes de Petites Tailles, the Fondation des Gueules Cassées, the Fondation pour la Recherche Médicale (FDT20150532684), and the Société Française de Biologie des Tissus Minéralisés.

Address correspondence to: Laurence Legeai-Mallet, INSERM U1163, Université Paris Descartes, Sorbonne Paris Cité, Institut Imagine, Paris, France. Phone: 00.33.1.42.75.43.02; E-mail: laurence.legeai-mallet@inserm.fr.
1. Baujat G, Legeai-Mallet L, Finidori G, CormierDaire V, Le Merrer M. Achondroplasia. Best Pract Res Clin Rheumatol. 2008;22(1):3-18.

2. Horton WA, Hall JG, Hecht JT. Achondroplasia. Lancet. 2007;370(9582):162-172.

3. Rousseau F, et al. Mutations in the gene encoding fibroblast growth factor receptor-3 in achondroplasia. Nature. 1994;371(6494):252-254.

4. Shiang R, et al. Mutations in the transmembrane domain of FGFR3 cause the most common genetic form of dwarfism, achondroplasia. Cell. 1994;78(2):335-342.

5. Colvin JS, Bohne BA, Harding GW, McEwen DG, Ornitz DM. Skeletal overgrowth and deafness in mice lacking fibroblast growth factor receptor 3. Nat Genet. 1996;12(4):390-397.

6. Pannier S, et al. Delayed bone age due to a dual effect of FGFR3 mutation in Achondroplasia. Bone. 2010;47(5):905-915.

7. Naski MC, Colvin JS, Coffin JD, Ornitz DM. Repression of hedgehog signaling and BMP4 expression in growth plate cartilage by fibroblast growth factor receptor 3. Development. 1998;125(24):4977-4988.

8. Iwata $\mathrm{T}$, et al. A neonatal lethal mutation in FGFR3 uncouples proliferation and differentiation of growth plate chondrocytes in embryos. Hum Mol Genet. 2000;9(11):1603-1613.

9. Legeai-Mallet L, Benoist-Lasselin C, Munnich A, Bonaventure J. Overexpression of FGFR3, Stat1, Stat5 and p21Cip1 correlates with phenotypic severity and defective chondrocyte differentiation in FGFR3-related chondrodysplasias. Bone. 2004;34(1):26-36.

10. Minina E, Kreschel C, Naski MC, Ornitz DM, Vortkamp A. Interaction of FGF, Ihh/Pthlh, and BMP signaling integrates chondrocyte proliferation and hypertrophic differentiation. Dev Cell. 2002;3(3):439-449.

11. Zhou ZQ, Ota S, Deng C, Akiyama H, Hurlin PJ. Mutant activated FGFR3 impairs endochondral bone growth by preventing SOX9 downregulation in differentiating chondrocytes. $\mathrm{Hum} \mathrm{Mol}$ Genet. 2015;24(6):1764-1773.

12. Murakami S, et al. Constitutive activation of MEK1 in chondrocytes causes Stat1-independent achondroplasia-like dwarfism and rescues the
Fgfr3-deficient mouse phenotype. Genes Dev. 2004;18(3):290-305.

13. Nowroozi N, et al. Sustained ERK1/2 but not STAT1 or 3 activation is required for thanatophoric dysplasia phenotypes in PC12 cells. Hum Mol Genet. 2005;14(11):1529-1538.

14. Wendt DJ, et al. Neutral endopeptidase-resistant C-type natriuretic peptide variant represents a new therapeutic approach for treatment of fibroblast growth factor receptor 3-related dwarfism. JPharmacol Exp Ther. 2015;353(1):132-149.

15. Lorget F, et al. Evaluation of the therapeutic potential of a CNP analog in a Fgfr3 mouse model recapitulating achondroplasia. Am J Hum Genet. 2012;91(6):1108-1114.

16. Xie Y, et al. Intermittent PTH (1-34) injection rescues the retarded skeletal development and postnatal lethality of mice mimicking human achondroplasia and thanatophoric dysplasia. Hum Mol Genet. 2012;21(18):3941-3955.

17. Garcia S, et al. Postnatal soluble FGFR3 therapy rescues achondroplasia symptoms and restores bone growth in mice. Sci Transl Med. 2013;5(203):203ra124.

18. Yamashita A, et al. Statin treatment rescues FGFR3 skeletal dysplasia phenotypes. Nature. 2014;513(7519):507-511.

19. Matsushita M, et al. Meclozine promotes longitudinal skeletal growth in transgenic mice with achondroplasia carrying a gain-of-function mutation in the FGFR3 gene. Endocrinology. 2015;156(2):548-554.

20. Guagnano V, et al. Discovery of 3-(2,6-dichloro3,5-dimethoxy-phenyl)-1-\{6-[4-(4-ethyl-piperazin1-yl)-phenylamino]-pyrimidin-4-yl\}-1-methylurea (NVP-BGJ398), a potent and selective inhibitor of the fibroblast growth factor receptor family of receptor tyrosine kinase. JMed Chem. 2011;54(20):7066-7083.

21. Gudernova I, et al. Multikinase activity of fibroblast growth factor receptor (FGFR) inhibitors SU5402, PD173074, AZD1480, AZD4547 and BGJ398 compromises the use of small chemicals targeting FGFR catalytic activity for therapy of short stature syndromes. Hum Mol Genet. 2016;25(1):9-23.

22. Wöhrle S, et al. Pharmacological inhibition of fibroblast growth factor (FGF) receptor signaling ameliorates FGF23-mediated hypophosphatemic rickets. J Bone Miner Res. 2013;28(4):899-911.

23. Wöhrle S, et al. Fibroblast growth factor receptors as novel therapeutic targets in SNF5deleted malignant rhabdoid tumors. PLoS One. 2013;8(10):e77652.

24. Scheller T, et al. mTOR inhibition improves fibroblast growth factor receptor targeting in hepatocellular carcinoma. Br JCancer. 2015;112(5):841-850.

25. Benoist-Lasselin C, et al. Human immortalized chondrocytes carrying heterozygous FGFR3 mutations: an in vitro model to study chondrodysplasias. FEBS Lett. 2007;581(14):2593-2598.

26. Gibbs L, Legeai-Mallet L. FGFR3 intracellular mutations induce tyrosine phosphorylation in the Golgi and defective glycosylation. Biochim Biophys Acta . 2007;1773(4):502-512.

27. Ornitz DM, Marie PJ. FGF signaling pathways in endochondral and intramembranous bone development and human genetic disease. Genes Dev. 2002;16(12):1446-1465.

28. Di Rocco F, et al. FGFR3 mutation causes abnormal membranous ossification in achondroplasia. Hum Mol Genet. 2014;23(11):2914-2925.

29. Pannier S, et al. Activating Fgfr3 Y367C mutation causes hearing loss and inner ear defect in a mouse model of chondrodysplasia. Biochim Biophys Acta. 2009;1792(2):140-147.

30. Jonquoy A, et al. A novel tyrosine kinase inhibitor restores chondrocyte differentiation and promotes bone growth in a gain-of-function Fgfr3 mouse model. Hum Mol Genet. 2012;21(4):841-851.

31. Chan WC, Au TY, Tam V, Cheah KS, Chan D. Coming together is a beginning: the making of an intervertebral disc. Birth Defects Res C Embryo Today. 2014;102(1):83-100.

32. Ornitz DM, Marie PJ. Fibroblast growth factor signaling in skeletal development and disease. Genes Dev. 2015;29(14):1463-1486.

33. Legeai-Mallet L, Benoist-Lasselin C, Delezoide AL, Munnich A, Bonaventure J. Fibroblast growth factor receptor 3 mutations promote apoptosis but do not alter chondrocyte proliferation in thanatophoric dysplasia. J Biol Chem. 1998;273(21):13007-13014.

34. Krejci P, et al. Analysis of STAT1 activation by 
six FGFR3 mutants associated with skeletal dysplasia undermines dominant role of STAT1 in FGFR3 signaling in cartilage. PLoS One. 2008;3(12):e3961.

35. Lefebvre V, Huang W, Harley VR, Goodfellow PN, de Crombrugghe B. SOX9 is a potent activator of the chondrocyte-specific enhancer of the pro alpha1(II) collagen gene. Mol Cell Biol. 1997;17(4):2336-2346.

36. Lefebvre V, de Crombrugghe B. Toward understanding SOX9 function in chondrocyte differentiation. Matrix Biol. 1998;16(9):529-540.

37. Sahni M, et al. FGF signaling inhibits chondrocyte proliferation and regulates bone development through the STAT-1 pathway. Genes Dev. 1999;13(11):1361-1366.

38. Sahni M, Raz R, Coffin JD, Levy D, Basilico C. STAT1 mediates the increased apoptosis and reduced chondrocyte proliferation in mice overexpressing FGF2. Development. 2001;128(11):2119-2129.

39. Muenke $M$, et al. A unique point mutation in the fibroblast growth factor receptor 3 gene (FGFR3) defines a new craniosynostosis syndrome. Am J Hum Genet. 1997;60(3):555-564.
40. Cappellen D, et al. Frequent activating mutations of FGFR3 in human bladder and cervix carcinomas. Nat Genet. 1999;23(1):18-20.

41. Chesi M, et al. The $t(4 ; 14)$ translocation in myeloma dysregulates both FGFR3 and a novel gene, MMSET, resulting in IgH/MMSET hybrid transcripts. Blood. 1998;92(9):3025-3034.

42. Carter EP, Fearon AE, Grose RP. Careless talk costs lives: fibroblast growth factor receptor signalling and the consequences of pathway malfunction. Trends Cell Biol. 2015;25(4):221-233.

43. Mugniery E, et al. An activating Fgfr3 mutation affects trabecular bone formation via a paracrine mechanism during growth. Hum Mol Genet. 2012;21(11):2503-2513.

44. Sebastian A, et al. Genetic inactivation of ERK1 and ERK2 in chondrocytes promotes bone growth and enlarges the spinal canal. JOrthop Res. 2011;29(3):375-379.

45. Trudel S, et al. Inhibition of fibroblast growth factor receptor 3 induces differentiation and apoptosis in $\mathrm{t}(4 ; 14)$ myeloma. Blood. 2004;103(9):3521-3528.

46. Grand EK, Chase AJ, Heath C, Rahemtulla A, Cross NCP. Targeting FGFR3 in multiple myeloma: inhibition of $\mathrm{t}(4 ; 14)$-positive cells by SU 5402 and PD173074. Leukemia. 2004;18(5):962-966.

47. De Brito LR, et al. Comparative pre-clinical evaluation of receptor tyrosine kinase inhibitors for the treatment of multiple myeloma. Leuk Res. 2011;35(9):1233-1240.

48. Aviezer D, Golembo M, Yayon A. Fibroblast growth factor receptor-3 as a therapeutic target for Achondroplasia - genetic short limbed dwarfism. Curr Drug Targets. 2003;4(5):353-365.

49. Reina V, et al. Craniovertebral junction anomalies in achondroplastic children. Adv Tech Stand Neurosurg. 2014;40:295-312.

50. Julliand S, et al. Lung function, diagnosis, and treatment of sleep-disordered breathing in children with achondroplasia. Am JMed Genet A. 2012;158A(8):1987-1993.

51. Engberts AC, Jacobs WC, Castelijns SJ, Castelein RM, Vleggeert-Lankamp CL. The prevalence of thoracolumbar kyphosis in achondroplasia: a systematic review. JChild Orthop. 2012;6(1):69-73.

52. Jeong ST, Song HR, Keny SM, Telang SS, Suh SW, Hong SJ. MRI study of the lumbar spine in achondroplasia. A morphometric analysis for the evaluation of stenosis of the canal. J Bone Joint Surg Br. 2006;88(9):1192-1196. 